\title{
INTERAÇÃO ENTRE ONDAS OCEÂNICAS E FUNDO MARINHO: RESULTADOS NA PLATAFORMA CONTINENTAL SETENTRIONAL DO RIO GRANDE DO NORTE
}

\section{INTERACTION BETWEEN OCEAN WAVE AND MARINE BOTTOM: RESULTS IN THE NORTHERN CONTINENTAL SHELF RN}

\author{
Maria de Fátima Alves de Matos \\ Departamento de Geologia, Universidade Federal do Rio Grande do Norte. \\ Campus Universitário, Lagoa Nova, Natal/RN, Cep: 59078-970, Brasil. \\ E-mail:mfatimaalves.m@gmail.com
}

Venerando Eustáquio Amaro

Departamento de Geologia, Universidade Federal do Rio Grande do Norte. Campus Universitário, Lagoa Nova, Natal/RN, Cep: 59078-970, Brasil.

E-mail: amaro@geologia.ufrn.br

Conceição Juana Fortes

Departamento de Hidráulica e Ambiente, Laboratório Nacional de Engenharia Civil. Av. do Brasil, 101, Lisboa, Cep: 1700-066, Portugal.

E-mail: jfortes@Inec.pt

Ada Cristina Scudelari

Departamento de Engenharia Civil, Universidade Federal do Rio Grande do Norte Campus Universitário, Lagoa Nova, Natal/RN, Cep: 59072-970, Brasil.

E-mail: ada@ct.ufrn.br

\section{Informações sobre o Artigo}

Data de Recebimento:

02/10/2013

Data de Aprovação:

30/06/2014

\section{Palavras-chave:}

Modelagem de ondas, fundo marinho raso, Rio Grande do Norte.

\section{Keywords:}

Wave modelling, shallow seabed, Rio Grande do Norte.

\section{Resumo:}

A plataforma continental setentrional do Rio Grande do Norte caracteriza-se por apresentar uma variedade de feições de fundo marinho que variam desde $10 \mathrm{~cm}$ até quilômetros, sobretudo submersos nas porções mais rasas da plataforma e indicam processos de retrabalhamento. Além do caráter singular dos processos, formas e fáceis de fundo diferenciados a qual esta plataforma está submetida, compreendese a importância do conhecimento da dinâmica das ondas, uma vez que estas são consideradas o agente forçador dominante na hidro e morfodinâmica costeira. O objetivo principal deste trabalho é caracterizar o clima de ondas por meio da modelagem numérica, através do modelo de ondas de superfície do mar, SWAN, e analisar sua interação com o fundo marinho raso da plataforma continental setentrional do Rio Grande do Norte. Foram realizadas várias medições de campo entre 2011 e 2012, com o objetivo de se obter os parâmetros de ondas: altura 
significativa (HS), período médio (Tmed), direção (DIR) para servir de comparação e validação da modelagem. Os resultados apontam que o SWAN conseguiu, no geral, reproduzir adequadamente o clima de ondas para este litoral. Entretanto, ao analisar os resultados, confirmou-se que as alturas significativas apresentam resultados mais aceitáveis em relação aos demais parâmetros. A interação da onda com o fundo marinho revela alteração das alturas significativas e direções ao propagarem-se sobre as formas de fundos presentes, como as rochas praiais, os campos de dunas longitudinais, transversais e subaquáticos. Tais resultados mostram que nesta plataforma continental o mecanismo de dissipação dominante à propagação das ondas nestas águas rasas é o atrito de fundo.

\begin{abstract}
:
The continental shelf at northern Rio Grande do Norte/Brazil is marked by a huge diversity of seafloor features ranging from $10 \mathrm{~cm}$ to kilometers. That is typically submerged in the shallow portions of the platform and indicates reworking processes. In addition the dynamics of waves are considered the dominant agent in hydro and morphodynamics processes. The paper aims to describe the wave climate through numerical modeling, using the sea surface waves model, SWAN, and analyze their interaction with the shallow seabed of the continental shelf at northern Rio Grande do Norte. Were used several field measurements from 2011 and 2012, to obtain wave parameters such as height (HS), period, (Tmed), direction (DIR) that provided a modeling validation and evaluation. The results show that overall SWAN could properly reproduce the wave climate for this coast. However, the statistics analyzes, confirmed that significant heights show more acceptable results than other parameters. Wave interaction with seabed reveals significant changes in heights and directions as they propagate toward shallow bottom, with beachrocks, longitudinal and transverse dunes. The last ones occur respectively as symmetrical and asymmetrical parallel to coast and parallel to underwater coast. Thus, the dominant dissipation mechanism to wave's propagation in these shallow waters is the friction bottom.
\end{abstract}

\section{Introdução}

O uso e a ocupação da zona costeira defrontam-se com ambiente de interface entre o continente, o oceano e a atmosfera. Portanto, as feições morfológicas encontradas nestas regiões representam a resposta da integração das contribuições dos agentes oriundos dos processos continentais, oceânicos e atmosféricos. Esta resposta se dá continuamente no tempo e está sujeita as variações de agentes motrizes e passivos de origem natural e/ou antrópica (ROSMAN et al., 2007). Sabidamente os processos físicos nestas zonas são fruto da superposição de efeitos de ondas, correntes, marés, ventos, configuração morfológica da costa (linha de costa, declividade dos taludes, materiais constituintes), entre outros fatores. Consequentemente, o processo de transformação de ondas geradas ao largo até a zona costeira tem implicações importantes no transporte de sedimentos, afetando assim diretamente a morfologia costeira.

Desta forma, o conhecimento detalhado da agitação marítima presente nesta zona é de fundamental importância, por exemplo, para o planejamento de construções de estruturas offshore, para fins de navegação, para o conhecimento da hidrodinâmica local e gerenciamento costeiro (AKPINAR et al., 2012). Uma maneira de se determinar a agitação marítima é basearse em dados de campo, cuja obtenção é uma tarefa difícil pelos equipamentos, meios humanos e financeiros que envolvem. Além disso, numa dada região de estudo, os dados quando existentes são pontuais e assim, com pouca representatividade espacial. A obtenção de dados que permitam uma adequada representação espacial e temporal do clima de ondas esbarra em dificuldades operacionais e econômicas, uma vez que exigem longos períodos de medição com ampla espacialização de estações de medição.

A modelação numérica do fenômeno, aliada às observações de campo, aparece como alternativa significativa para a caracterização da agitação marítima, uma vez que permite prever as características do clima de ondas de dada região e, sobretudo, permite sua análise a curto, médio e longo prazo.

Os modelos numéricos integram e extrapolam informações a partir de medições e descrevem a hidrodinâmica e processos de dispersão de constituintes, minimizando gastos, otimizando as redes de monitoramento e permitindo a definição de estratégias de ação, ou mesmo favorecendo simulações de alterações na 
geometria das zonas costeiras. A aplicação dos modelos numéricos tem sido usada extensivamente nas últimas décadas para responder questões relativas à hidrodinâmica e a qualidade das águas em zonas costeiras, estuários, lagos, lagoas, baías e reservatórios.

Seus progressos recentes na capacidade de previsão e melhorias na precisão de campos de vento (hindcast) têm permitido implementar modelos mais precisos de $3{ }^{a}$ geração, incluindo tanto as condições offshore e nearshore (AKPINAR et al., 2012). Este fato tem contribuído para estudos de eventos passados, a partir das simulações dos dados atmosféricos pretéritos (hindcasting), assim como na previsão de cenários futuros, forçando os modelos às condições de análises e previsões (forecasting) (CUCHIARA et al., 2006). Porém, qualquer modelo numérico de propagação ou geração de ondas é baseado em aproximações e hipóteses, o que faz com que apresentem limitações na descrição precisa das ondas na zona em estudo. Devido à maioria dos modelos numéricos envolverem uma série de parâmetros que têm que ser calibrados para cada caso de estudo, reforça-se assim a importância de aliar a modelação numérica a observações de campo. E um dos principais exemplos de problemas e limitações existentes para se avançar no conhecimento sobre como modelar as ondas geradas por vento em águas rasas e muito rasas é a falta de dados a partir de medições in situ.

Diferentemente do que ocorre em águas profundas, a dinâmica de ondas em áreas de águas rasas é dominada pela interação com o fundo (PADILLA -HERNÁNDEZ e MONBALIU, 2001). É por este fato que nas zonas costeiras o mecanismo de dissipação considerado dominante é o atrito de fundo, onde a força relativa depende das características de fundo, tipo de sedimento e geometria da ondulação do fundo (ARORA e BHASKARAN, 2012).

Sendo assim, o principal objetivo deste trabalho é o uso do modelo de ondas SWAN, acrônimo de Simulating WAves Nearshore (BOOIJ et al., 1999), para caracterizar o clima de ondas (altura, HS, período, Tmed, direção, DIR) e sua interação com o fundo marinho raso da plataforma continental setentrional do Rio Grande do Norte. Plataforma esta, com características próprias conforme a variação de profundidades, e por isso, apresenta processos e formas de fundo diferenciadas ao longo dela (VITAL et al., 2005; 2008; LIMA et al., 2006; TABOSA e VITAL, 2006; TABOSA et al., 2007; GOMES e VITAL, 2010).

Existem vários modelos de geração e/ou propagação de ondas que de maneira geral resultam na determinação das características das ondas que incidem na região (altura, período médio, direção média, dentre

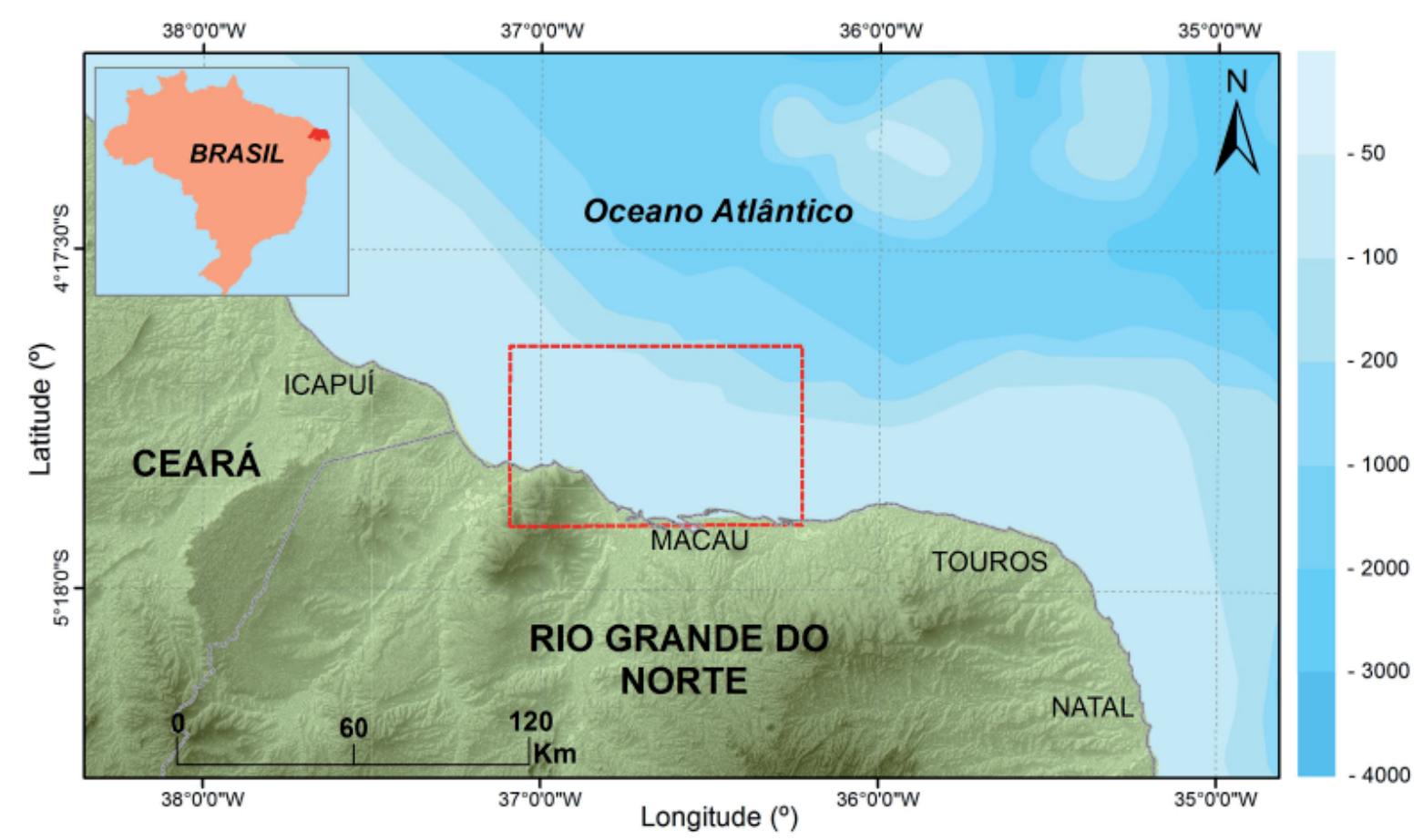

Figura 1 - Litoral norte do Rio Grande do Norte (área de estudo em retângulo vermelho). 
outras).

Em muitos casos a definição de um modelo hidrodinâmico ou numérico a ser usado é justificado pela escolha do modelo a ser utilizado em cada caso levando em consideração os principais efeitos e as limitações de cada modelo (FORTES et al., 2004), ou ainda pelas condições de natureza técnica e econômica para a realização da coleta de dados em campo. A interação entre dados de campo e a modelagem matemática resulta na possibilidade concreta da reprodução das condições reais do sistema por parte do modelo (ARAÚJO e JORGENSEN, 1988).

A definição do modelo SWAN para esta região, esta nas vantagens operacionais que o modelo oferece: é um modelo de utilização aberta (freeware); possui a capacidade de modelar grandes regiões geográficas, como é o caso deste litoral do RN; sua execução em modo estacionário e não estacionário (resultando em tempo de cálculo e memória computacional); outro fator que definiu o uso deste modelo está na determinação da onda ser mais bem caracterizada no SWAN, devido este modelo contar com maior número de fenômenos físicos que influenciam a propagação da onda; além dos resultados dos parâmetros de ondas serem em cada ponto do domínio geográfico da área modelada.

Portanto, na primeira fase deste trabalho, o SWAN foi aplicado para caracterização do clima de ondas para vários períodos de medições in situ, efetuadas para dois pontos localizados próximos da costa entre os anos de 2011 e 2012; em seguida, fez-se uma análise comparativa entre os resultados da modelagem com os dados medidos, por meio de parâmetros estatísticos para uma adequada validação e análises dos resultados. Com base nos resultados simulados pelo SWAN, obteve-se uma descrição da evolução espacial do clima de ondas para todo o domínio da malha computacional para analisar a agitação marítima no período de verão e no período de inverno, e, finalmente, uma análise da evolução das ondas em águas rasas. E, finalizando são feitas as devidas conclusões.

\section{Material e Métodos}

\subsection{Medições in situ e Dados de Ondas Válidos}

As informações in situ utilizadas referem-se às campanhas de campo realizadas em 2011 e 2012, em dois pontos posicionados próximos da costa (Figura 2), obtidos por meio de dois perfilhadores acústicos de ondas (ADCP), identificados com PT 1 (AQUADOPP) e PT 2 (AWAC) configurados para aquisição com frequência de $1 \mathrm{~Hz}$ e sensores de ângulo reto. Na Tabela 1 , são apresentados o conjunto de todas as medições para as duas estações, os parâmetros obtidos foram: altura significativa (HS), período médio (s) e direção $\left(^{\circ}\right)$.

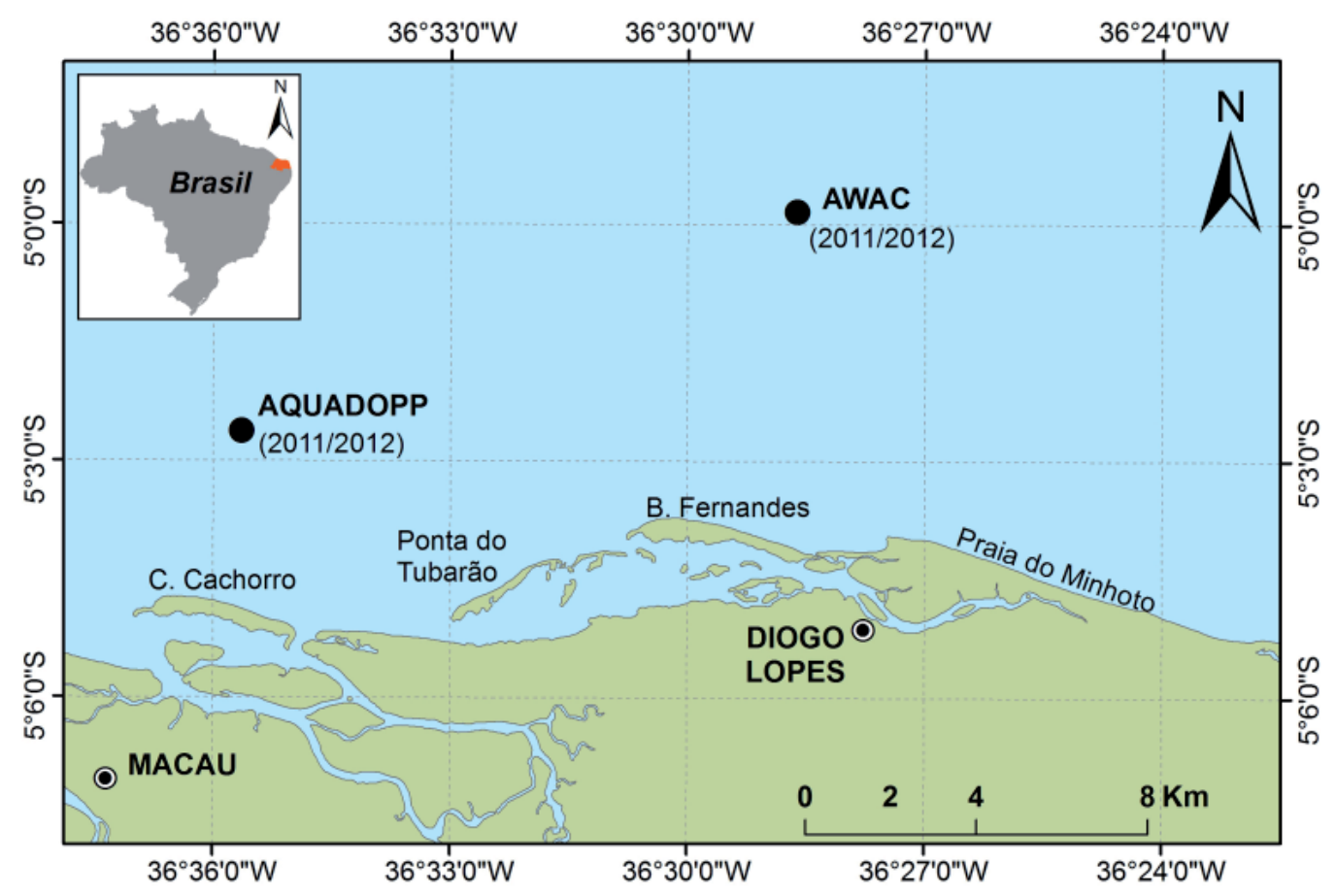

Figura 2 - Mapa de localização dos pontos de medições dos dados de ondas. 
Tabela 1: Características dos locais de coleta para cada instrumento usado nas campanhas: AQUADOPP e AWAC.

\begin{tabular}{|c|c|c|c|c|c|}
\hline Estação & $\begin{array}{l}\text { Instrumento } \\
\text { (ADCP) }\end{array}$ & $\begin{array}{c}\text { Freq. Acústica } \\
\text { (MHz) }\end{array}$ & Prof. (m) & $\begin{array}{c}\text { Localização } \\
\text { UTM-Z-24-S } \\
\end{array}$ & Data de Coleta \\
\hline PT 1 & AQUADOPP & 1.0 & $3-4$ & $\begin{array}{l}X=766768 \\
Y=9441999\end{array}$ & $\begin{array}{l}07 \text { a } 22 / 02 / 2011 \\
22 \text { a } 27 / 08 / 2012\end{array}$ \\
\hline PT 2 & AWAC & 1.0 & $7-8$ & $\begin{array}{l}X=779765 \\
Y=9447091\end{array}$ & $\begin{array}{l}01 \text { a } 07 / 01 / 2011 \\
23 \text { a } 25 / 08 / 2012\end{array}$ \\
\hline
\end{tabular}

Na seção seguinte, nas Tabelas 2 e 3, são apresentados um resumo dos resultados dos dados válidos para os parâmetros de ondas dos dois pontos de medições: altura significativa, HS (m), período médio, Tmed (s) e direção da onda, DIR $\left({ }^{\circ}\right)$ para as condições de agitação das estações de medições do PT 1 e PT 2.

Nos resultados obtidos para as campanhas do PT 1 (Tabela 2), mostraram diferentes condições de agitação marítima nos períodos observados. Em fevereiro, observa-se um estado de mar menos agitado com alturas significativas máximas de 1,25 m e períodos médios máximos de 7,48 s. Em agosto, observa-se uma oscilação marítima mais agitada, com alturas máximas de 2,49 e períodos médios de 4,74 s.

Nos resultados das campanhas do segundo ponto, PT 2 (Tabela 3), nota-se que em janeiro, as alturas significativas são maiores que as de abril quando o mar está menos agitado neste período, com $1,88 \mathrm{~m}$ e períodos médios de $8 \mathrm{~s}$, e, $0,88 \mathrm{~m}$ e 5,6 s, respectivamente.

Tabela 2: Características da agitação marítima do PT 1: altura significativa (HS), período médio (s) e direção ( $\left.{ }^{\circ}\right)$. Dados observados em fevereiro de 2011 e agosto de 2012.

\begin{tabular}{|c|c|c|c|c|c|c|}
\hline \multirow[t]{2}{*}{ Parâmetros } & \multicolumn{3}{|c|}{$\begin{array}{c}\text { Ondas Observadas } \\
\text { (07 a 22/02/2011) }\end{array}$} & \multicolumn{3}{|c|}{$\begin{array}{c}\text { Ondas Observadas } \\
\text { (22 a 27/08/2012) }\end{array}$} \\
\hline & HS (m) & Tmed (m) & $\operatorname{DIR}\left({ }^{\circ}\right)$ & HS (m) & Tmed (m) & $\operatorname{DIR}\left({ }^{\circ}\right)$ \\
\hline Máximo & 1,25 & 7,48 & 359 & 2,49 & 4,74 & 359 \\
\hline Média & 0,73 & 4,78 & 177 & 0,80 & 2,81 & 193 \\
\hline Mínimo & 0,39 & 3,19 & 1 & 0,30 & 1,87 & 3 \\
\hline N. de amostras & 715 & 715 & 715 & 151 & 151 & 151 \\
\hline Erro Padrão & 0,01 & 0,03 & 3 & 0,05 & 0,03 & 8,9 \\
\hline Desvio Padrão & 0,15 & 0,82 & 91 & 0,64 & 0,40 & 109 \\
\hline
\end{tabular}

Tabela 3: Características da agitação marítima do PT 2: altura significativa (HS), período médio (s) e direção ( $\left.{ }^{\circ}\right)$. Dados observados em janeiro de 2011 e abril de 2012.

\begin{tabular}{|c|c|c|c|c|c|c|}
\hline \multirow{2}{*}{ Parâmetros } & \multicolumn{3}{|c|}{$\begin{array}{c}\text { Ondas Observadas } \\
\text { (01 a 07/0/2011) }\end{array}$} & \multicolumn{3}{|c|}{$\begin{array}{c}\text { Ondas Observadas } \\
\text { (17 a 24/04/2012) }\end{array}$} \\
\hline & HS (m) & Tmed (m) & $\operatorname{DIR}\left(^{(}\right)$ & HS (m) & Tmed (m) & $\operatorname{DIR}\left(^{\circ}\right)$ \\
\hline Máximo & 1,88 & 8,00 & 359 & 0,88 & 5,60 & 356 \\
\hline Média & 1,04 & 4,82 & 77 & 0,54 & 4,65 & 177 \\
\hline Mínimo & 0,58 & 3,06 & 1 & 0,38 & 4,05 & 3 \\
\hline N. de amostras & 339 & 339 & 339 & 97 & 97 & 97 \\
\hline Erro Padrão & 0,01 & 0,04 & 5,8 & 0,01 & 0,03 & 10 \\
\hline Desvio Padrão & 0,26 & 0,87 & 106 & 0,11 & 0,37 & 104 \\
\hline
\end{tabular}




\subsection{O modelo de Onda - SWAN}

O SWAN é modelo de ondas de superfície do mar utilizado para fornecer estimativas realistas de parâmetros de ondas em mar aberto, zonas costeiras, lagos e estuários influenciados por ventos, superfície de fundo e condições de correntes (PADILLA-HERNÁNDEZ e MONBALIU, 2001). É um modelo computacional de agitação espectral de terceira geração desenvolvido pela Universidade de Tecnologia de Delft.

Seu princípio físico é o mesmo de outros modelos, como por exemplo, o ciclo 3 do WAM. Porém, enquanto o WAM considera problemas de em escala oceânica, o SWAN calcula a propagação das ondas desde águas profundas até a zona de rebentação. A principal diferença está na utilização de métodos implícitos pelo SWAN, que são mais robustos em águas profundas que os explícitos, o que torna pouco indicado para escalas oceânicas (HOLTHUIJSEN et al., 1999; RIS et al., 1999; BOOIJ et al., 1999; HOLTHUIJSEN et al., 2003; ZIJLEMA e VAN DER WESTHUYSEN, 2005) descreveram a base teórica e numérica do SWAN.

Além destas características, o que definiu o uso do SWAN foram algumas vantagens em relação aos outros modelos numéricos, tipo: utilização aberta (freeware); sua execução em modo estacionário e não estacionário (resultando em tempo de cálculo e memória computacional); a caracterização da onda é melhor no SWAN, devido este contar com maior número de fenômenos que influenciam a propagação da onda; e, os resultados dos parâmetros de ondas em cada ponto do domínio geográfico da área modelada.

O modelo é baseado na equação de equilíbrio de ação. A equação definida pelo SWAN é expressa na equação (2.1).

$$
\frac{\partial}{\partial t} N+\frac{\partial}{\partial x} c_{x} N+\frac{\partial}{\partial y} c_{y} N+\frac{\partial}{\partial \sigma} c_{\sigma} N+\frac{\partial}{\partial \theta} c_{\theta} N=\frac{S}{\sigma}
$$

(Equação 2.1)

onde, $N(\sigma, \theta)$ é a densidade da ação da onda $(=F(\sigma, \theta /$ $\sigma) ; F$ é a densidade de energia da onda; $t$ é o tempo; $\sigma$ é a frequência relativa; $\theta$ é a direção da onda; $c_{x}, c_{y}$ são as velocidades de propagação geográficas $\mathrm{x}-, \mathrm{y}$ - espaciais; $c_{\sigma}$ e $c_{\theta}$ e são as velocidades de propagação no espectro espacial (frequência e direção espacial). $\mathrm{O}$ primeiro termo da equação (2.1) representa a taxa de locais de mudança de densidade de ação no tempo. O segundo e terceiro termos representam a propagação de ação no espaço geográfico. O quarto termo expressa a mudança de densidade de ação no espaço de frequência, devido as variações de profundidade e corrente. E o quinto termo reproduz a refração, profundidade induzida e corrente induzida.

Três diferentes mecanismos de dissipação podem ser observados no SWAN, isto é, dissipação por whitecapping, fricção com o fundo e quebra de onda induzida pela profundidade. Em águas de profundidade intermediária ou rasa $\mathrm{o}$ atrito de fundo torna-se importante. Ao aproximar-se da linha de costa, a quebra de onda induzida pela profundidade se torna dominante, e finalmente é dissipada toda a energia da onda (RIS et al., 1997).

Em águas rasas os movimentos orbitais das partículas líquidas estendem-se ao fundo. $\mathrm{O}$ atrito de fundo surge assim, no contexto da transferência de energia, como resultado da interação das partículas líquidas com o fundo (SAMPAIO, 2008). Várias formulações foram sugeridos para o atrito no fundo, o modelo SWAN utiliza três formulações distintas baseadas na equação (2.2) (ÂNGELO, 2012). O SWAN assume este valor por omissão, portanto, pode ser alterado no código de entrada:

$$
S_{d s, b}(\sigma, \theta)=-c \frac{\sigma^{2}}{g^{2} \sinh ^{2} k h} E(\sigma, \theta)
$$

(Equação 2.2)

À medida que a profundidade diminui, a energia da onda concentra-se continuamente até promover sua rebentação, dissipando rapidamente energia. Tal fenômeno é representado no modelo SWAN como se segue expressa na equação (2.3) (ÂNGELO, 2012):

$$
S_{d s, b r}(\sigma, \theta)=\frac{D_{t o t}}{E_{t o t}} E(\sigma, \theta)
$$

(Equação 2.3)

sendo $D_{\text {tot }}$ a taxa média de dissipação de energia da onda, por unidade horizontal de superfície (RIS, 1997).

Expressamente, os termos de origem no SWAN incluem o crescimento da energia da onda pela entrada do vento; a transferência de energia das ondas, devido 
interação não linear entre ondas (quádruplas e tríades); decaimento da energia da onda devido à whitecapping; atrito de fundo; e rebentação induzida pelo fundo.

A descrição detalhada do modelo SWAN, os termos fonte incorporados e o método numérico podem ser encontrados em diversos autores (RIS, 1997; HOLTHUIJSEN et al., 1999; BOOIJ et al., 1999).

A zona em estudo pode ser descrita com coordenadas cartesianas ou esféricas, utilizando uma malha "retangular" (CAPITÃO e FORTES, 2011).

Os dados necessários para a execução do SWAN são a malha batimétrica da zona de estudo, as condições de agitação na fronteira de entrada do domínio, além de um conjunto de outros parâmetros de cálculo.

Para a preparação dos dados, execução e visualização dos resultados do modelo SWAN foi utilizado a ferramenta SOPRO (FORTES et al., 2007).

De entre as limitações do modelo refira-se:

A calibração de muitos dos parâmetros envolvidos na descrição dos diferentes fenômenos físicos no SWAN utilizou dados da campanha JONSWAP, que foi realizada no Mar do Norte (HASSELMANN et al., 1973).

Outro ponto importante é a influência das condições de fronteira nos resultados do modelo SWAN em certas zonas do domínio de cálculo, como por exemplo, as condições de ventos continentais constantes.

\subsection{Configurações do Modelo SWAN}

Para alcançar o objetivo deste trabalho, foi aplicado o modelo numérico de ondas SWAN (BOOIJ et al., 1999), na versão $40.72 \mathrm{AB}$, em modo estacionário com as formulações KOMEN ${ }^{1}$, com rodagens e programações computacionais contínuas. $\mathrm{O}$ detalhamento dos parâmetros necessários, o domínio computacional e os fenômenos físicos envolvidos no processamento do SWAN encontram-se descritos a seguir.

\section{Condições de Agitação ao Largo}

Consideraram-se como condições ao largo os estados de mar ao largo estimados pelo modelo de $3^{\mathrm{a}}$ geração e propagação de ondas WAVEWATCH (WWIII) (TOLMAN, 2002), da boia oceânica da NOAA localiza- da na costa nordeste do Brasil nas coordenadas: latitude $-3^{\circ} \mathrm{S}$ e longitude $-36^{\circ} \mathrm{W}$ (Figura $3 \mathrm{~A}$ ). Estas estimativas contêm os parâmetros de onda seguintes: HS (altura de onda significativa), TP (período de pico) e DIR (direção de onda associada ao período de pico), obtidas a cada ciclo de três horas (Tabela 4), em conformidade às campanhas de medições em duas estações situadas próximas à costa conforme a Figura 2.

Uma vez conhecidas as estimativas do estado ao largo, caracterizado pela sua altura de onda significativa, HS, período de pico, TP, e a direção média/pico, DIR, o modelo SWAN transfere esses valores para a zona de estudo.

\section{Domínio Computacional e Condições de Fronteira do Modelo SWAN}

Para a execução do SWAN é necessário um conjunto de dados de entrada esquematizado num sistema de malhas encaixadas que compreende calcular os parâmetros correspondentes aos pontos da malha global, denominada de malha 1 (Figura 3A), utilizando-os depois como novas condições de fronteira para forçar a malha 2 (Figura 3B). Após concluir a malha 2, os parâmetros calculados são transferidos para a fronteira da malhar interior, ou malha 3 (Figura 3C) e, a semelhança do processo de transferencia descrito para as malha $1 \mathrm{e}$ 2, o modelo SWAN é novamente corrido, fornecendo finalmente os parâmetros de agitação marítima junto a costa e mais precisamente, para os pontos PT 1 e PT 2 analisados (MATOS, 2013).

Este sistema de malhas encaixadas fornece melhores resultados que os sistema de apenas um malha, principalmente, por mitigar os erros que poderão resultar da inexistencia de condições de fronteira nos limites laterais, Este e Oeste, do domínio da malha 1 (PIRES SILVA et al., 2000; TELES et al., 2012; ÂNGELO, 2012). As dimensões e resoluções de cada malha utilizada neste estudo estão resumidas na Tabela 4.

Além, da batimetria e malhas computacionais, os parâmetros de agitação ao largo, essencialmente são inseridos os valores de ventos, níveis de maré, etc., onde na Tabela 4 encontram-se especificados os dados de entrada e as respectivas referências de origens das informações. 

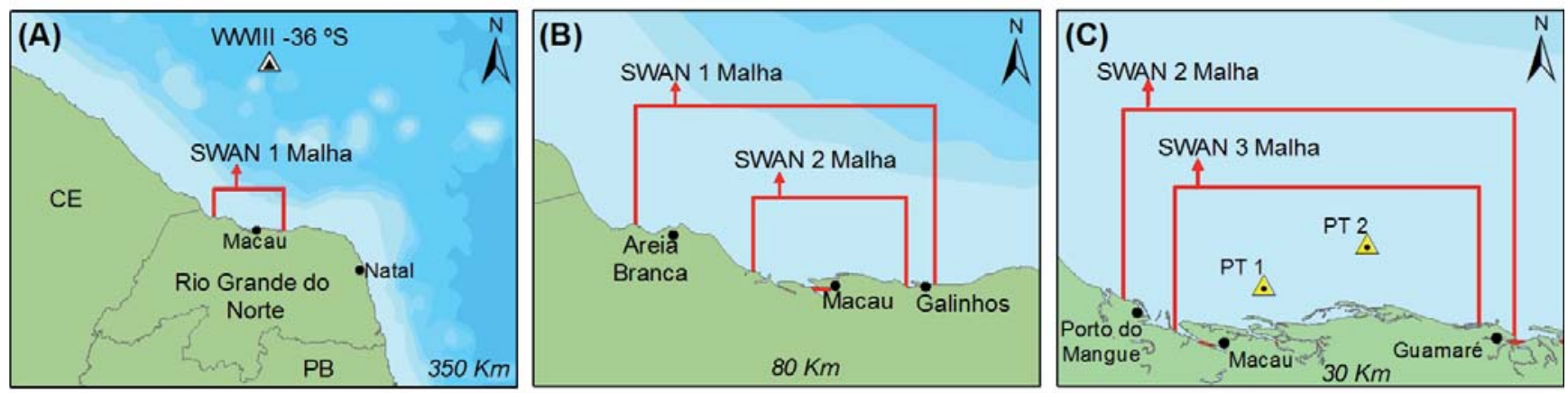

Figura 3 - Localização do ponto WWIII (A) e domínios computacionais (A, B e C).

Tabela 4: Condições de fronteira do SWAN e dados de origem.

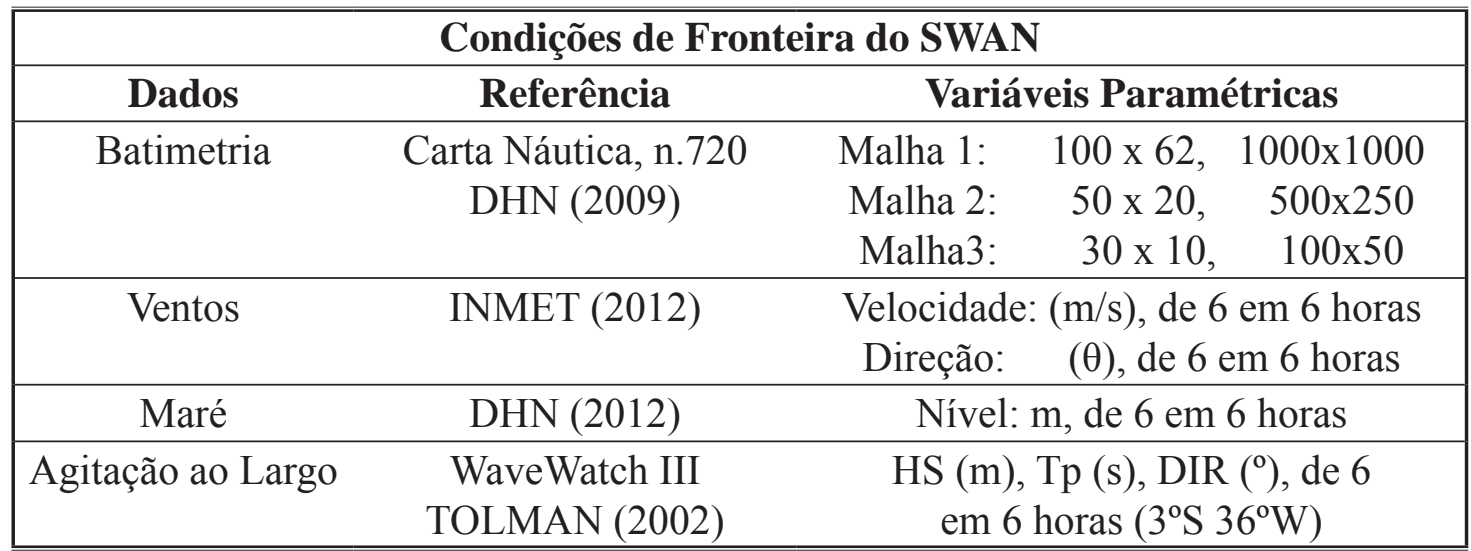

Para além destas condições de fronteira introduzidos nos cálculos do SWAN, foram inseridos os fenômenos físicos relacionados, sendo os mesmo indicados na Tabela 5 o tipo de fenômeno envolvido e as ferências de origem. O coeficiente de atrito de fundo atribuído foi o valor de $0.015 \mathrm{~m}^{2} \mathrm{~s}^{-3}$.

\subsection{Parâmetros Estatísticos e Medidas de Erro}

Os modelos de previsão necessitam ser validados. Esta validação permite obter conclusões gerais acei- táveis a cerca da comparação dos dados dos valores previsto em relação os dados medidos.

Os parâmetros estatísticos calculados permitem ter conclusões principalmente sobre a validade do modelo. Com base nestas conclusões, será possível analisar se o modelo se adéqua a zona costeira em estudo e se fornece resultados próximos dos reais.

A primeira análise foi à estatística descritiva dos dados previstos e dos dados medidos, em seguida, os parâmetros estatísticos calculados foram: o erro médio

Tabela 5: Fenômenos físicos incluídos para a aplicação do modelo numérico e as referencias.

\begin{tabular}{ll}
\hline Fenômenos Físicos & Referência \\
\hline Onda de crescimento linear & KOMEN et al. (1984) \\
Whitecapping & HASSELMANN (1974); \\
& WAMDI Group (1988) \\
Interações onda-onda quádrupla & HASSELMANN et al. (1985) \\
Interações entre tríades de ondas & ELDEBERKY (1996) \\
Atrito de fundo & HASSELMANN et al. (1973) \\
Rebentação induzida pelo fundo & BATTJES e JANSSEN (1978) \\
\hline \hline
\end{tabular}


quadrático (RMSE) e do índice de concordância ou reajuste, representado pela letra $d$ foram usados para comparação dos valores previstos e medidos (WILMOTT, 1981), também foi calculado o coeficiente de correlação de PEARSON e o gráfico de dispersão para as alturas significativas da onda.

Os parâmetros estatísticos foram calculados como segue abaixo:

Erro Quadrático Médio - RMSE

$$
R M S E=\sqrt{\frac{1}{N} \sum_{i=1}^{n}\left(O_{l}-P\right)^{2}}
$$

Coeficiente de correlação - PEARSON

$$
r=\frac{\sum(x-\bar{x})(y-\bar{y})}{\sqrt{\sum(x-\bar{x})^{2} \sum(y-\bar{y})^{2}}}
$$

(Equação 2.5)

Índice de Concordância "d” (WILLMOTT, 1981)

$$
d=1-\frac{\sum_{i=1}^{n}\left(O_{i}-P_{i}\right)^{2}}{\sum_{i=1}^{n}\left(\left|P_{i}-\bar{O}\right|+\left|O_{i}-\bar{O}\right|\right)^{2}}
$$

onde, d é o índice de concordância, $O_{i}$ são os valores medidos, $P_{i}$ são os valores dos modelos numéricos, ō é a medida do valor experimental e $n$ é o número de observações. Este índice varia de 0 a 1 , sendo que quanto mais próximo do 1 , menor será a escala de erros.

\section{Resultados e Discussões}

\subsection{Comparação da Simulação do SWAN em relação aos Dados do ADCP}

A partir da figura 3 até a figura 5, são apresentadas as características e validação do modelo SWAN, para cada período de medição do PT 1 e da figura 6 até a figura 10 os resultados para cada período de medição do PT 2.

Vale ressaltar que as análises foram referidas para os resultados do domínio da malha 1, a malha interna, por esta fornecer os parâmetros da agitação marítima junto à costa, precisamente para os locais de medições a serem comparados.

A validação é efetuada para altura significativa, período médio e direções médias. A comparação entre os resultados permite ter conclusão direta sobre os resultados simulados. Na análise dos resultados da Figura 4, pode se concluir que os resultados simulados conseguem representar a evolução dos parâmetros analisados. Apesar de que nas condições dos dias de fevereiro de 2011, as diferenças foram poucas entre os simulados e os dados reais. Outra observação que se pode extrair é uma concordância entre as tendências de crescimento e decaimento entre os valores reais e simulados, sendo bem apreendido pelo SWAN ao longo da evolução das alturas significativas e períodos médios, sendo bem captado pelo SWAN, isso se deve a intensificação dos ventos nesta região, e em alguns momentos quando ocorre à própria sobreposição de uma oscilação mais expressiva, nos episódios de picos.

Outra característica notada na Figura 4, em relação às alturas significativas de fevereiro de 2011, o SWAN superestimou em relação os dados do ADCP em toda a condução dos dias de medições, diferentemente para as análises dos dias de agosto de 2012, quando este, os dados simulados foram subestimados em relação os dados reais.

Nos casos dos períodos médios e das direções, houve uma subestimação, essencialmente em relação à condição dos dias de análises de agosto de 2012. Tal característica já fora observado em por ÂNGELO (2012) e por MATOS et al., (2013), quando estes analisaram condições similares nesta mesma região, com período médios simulados muito inferiores aos medidos.

Tais valores baixos podem ser devido à influência do coeficiente de atrito de fundo, $c$, uma vez que a diminuição do valor de $c$ leva a uma menor subestimação de Tmed, entretanto, ao usar valores de $c$ muito baixos, pode conduzir a superestimação da altura significativa da onda.

Nas análises comparativas em relação às medições do PT 2, apresentados na Figura 5, no geral, observou-se alguns fenômenos semelhantes aos apresentados para as condições de agitação relacionados ao PT 1, essencialmente no que corresponde aos períodos médios, com uma subestimação crônica do SWAN dos valores de Tmed (s). Entretanto, este ponto está localizado em profundidade muito além da do ponto anterior e muito 

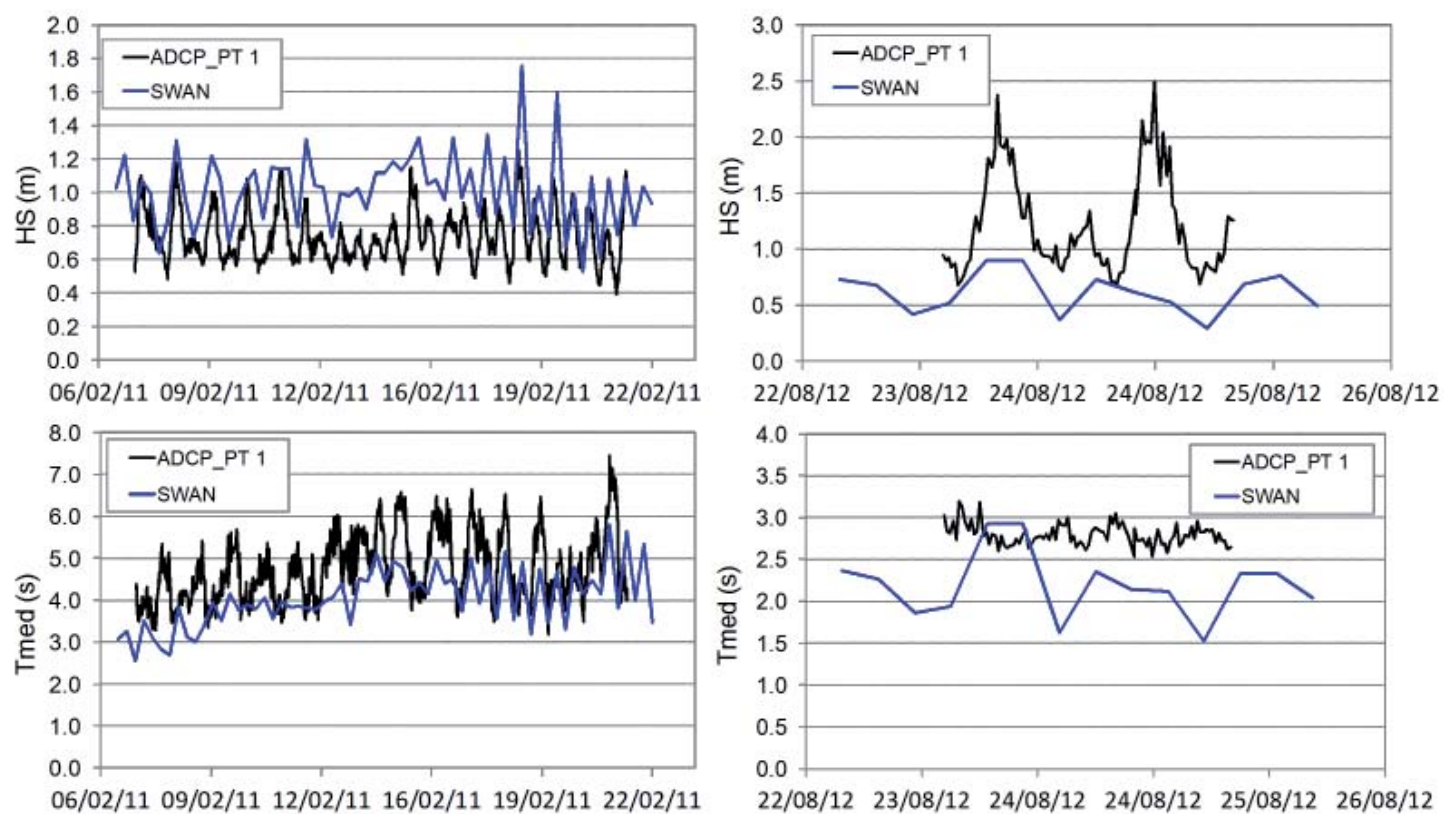

06/02/11 09/02/11 12/02/11 16/02/11 19/02/11 22/02/11
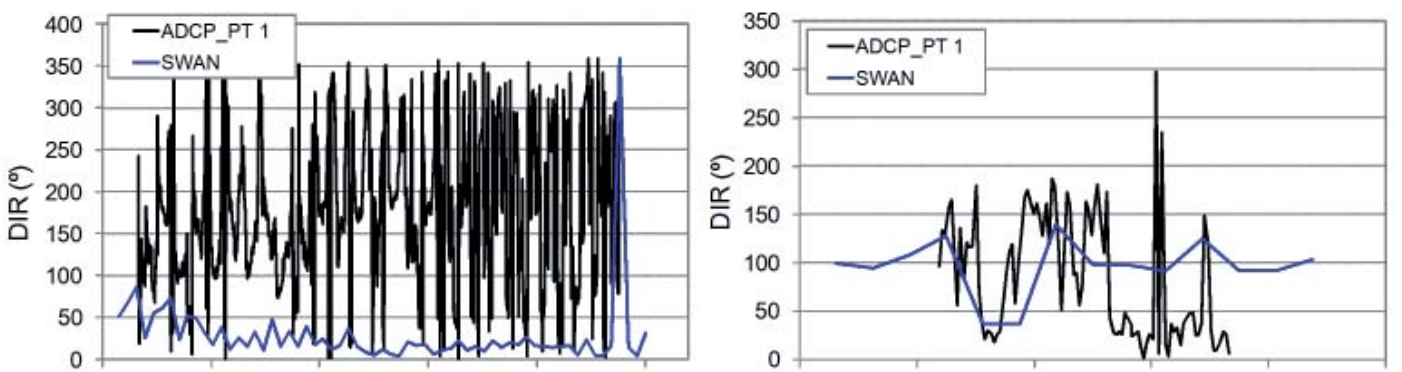

06/02/11 09/02/11 12/02/11 16/02/11 19/02/11 22/02/11

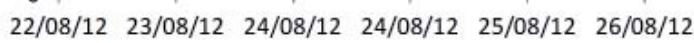

Figura 4 - Comparação dos resultados simulados (SWAN) com as medições (ADCP) do PT 1. A) Período de 07 a 22 de fevereiro de 2011; B) Período de 23 a 25 de agosto de 2012.

mais distante da costa, ou seja, os padrões de ondas, simulados e medidos, alteram significativamente para esta condição. Outro fator observado quanto às direções das ondas, obtiveram no geral um melhor ajustamento nas comparações, ainda que de pequenas grandezas, entretanto, não podem ser desconsideradas.

A tendência do crescimento e decaimento entre os valores das alturas significativas são relativamente mais concordantes como se pode observar nos casos das análises de janeiro de 2011. Ocorre uma maior aproximação entre os valores na fase inicial, embora aconteça também incidência de episódios de picos devido à sobreposição de ondulações mais expressivas durante a simulação. Em relação à entrada de ondulações mais expressivas, $o$ SWAN respondeu adequadamente as variações impostas a largo, como o ocorrido nas análises das comparações do PT 1 para as alturas significativas.
Em termos de período médio, notadamente, os resultados do SWAN, em comparação com as medições, apresentou uma tendência similar para o período de fevereiro de 2011, simulando bem o Tmed, entretanto, foi subestimado em relação os dados medidos.

No caso das direções, ao observar não somente o parâmetro estatístico, mais também as tendências, nota-se que conduzem um melhor desempenho. De qualquer forma tanto para as condições de agitação do PT 1 quanto do PT 2, os resultados das direções de ondas mantêm-se impassível para as diferentes simulações.

No geral o modelo SWAN conseguiu reproduzir o clima de ondas para a região do litoral do Rio Grande do Norte, embora as alturas significativas mostrarem-se com melhores resultados, pode-se extrair algumas conclusões que explicam o comportamento abaixo do esperado. Nessas elações, pode-se concluir que o uso da 

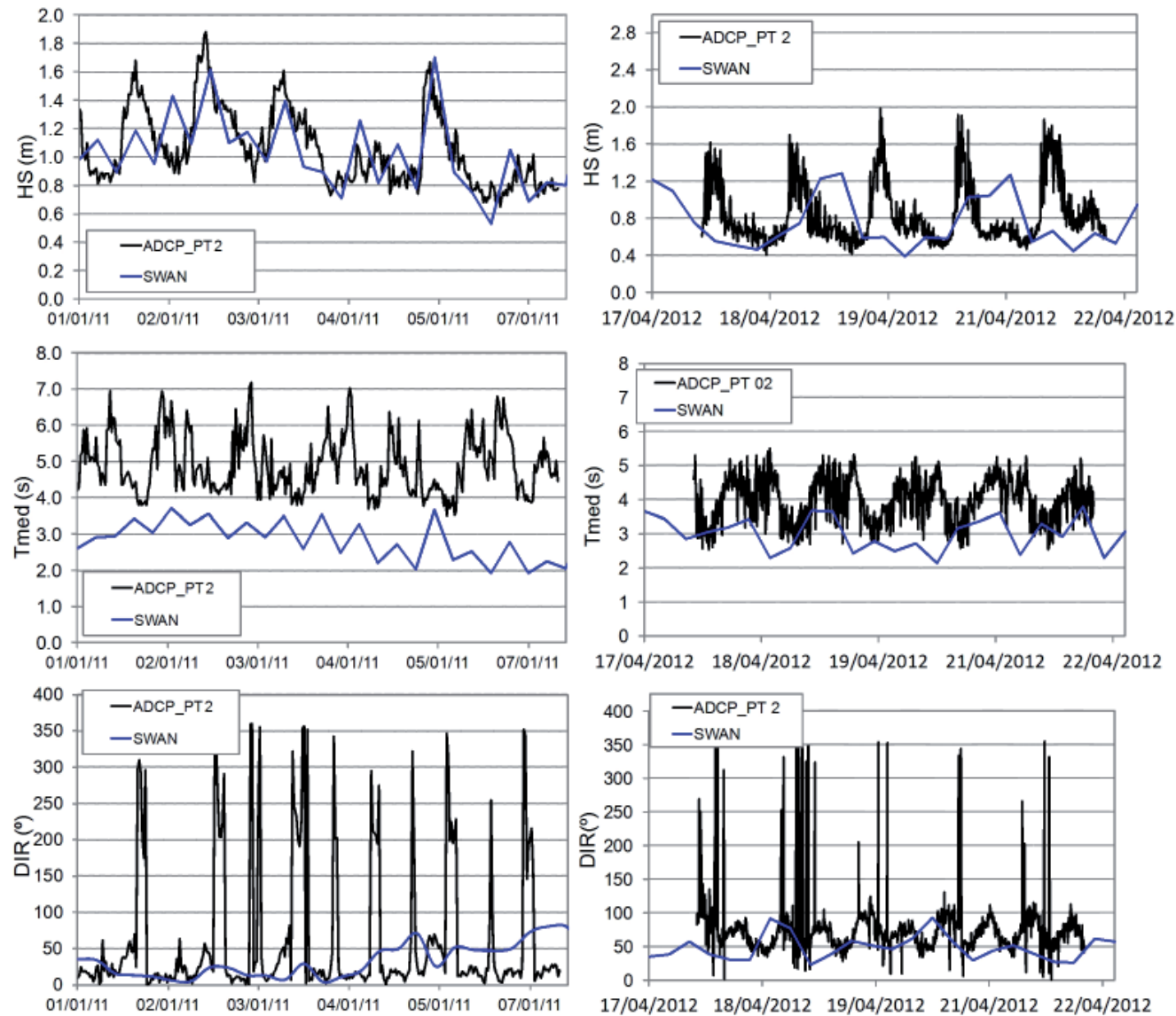

Figura 5 - Comparação dos resultados simulados (SWAN) com as medições (ADCP) do PT 1. A) Período de 07 a 22 de fevereiro de 2011; B) Período de 23 a 25 de agosto de 2012.

mesma formulação, no caso a formulação KOMEN para todo o conjunto da modelagem pode ter influenciado nos dados simulados, o que explica a discrepância entre os dados apresentados. Pois, uma mesma formulação para todo o conjunto de dados nem sempre reproduz melhores resultados para todos os parâmetros.

Outra conclusão, esta relacionada ao mesmo valor do coeficiente de atrito de fundo, $c$, no caso, o valor atribuído foi $c=0.015 \mathrm{~m}^{2} \mathrm{~s}^{-3}$, ora superestima as alturas significativas ou ora subestima os períodos médios. Sugerindo que o valor do atrito de fundo é importante se considerado, e a forma mais adequada é o uso do melhor valor que ajuste e modele melhor cada parâmetro estudado.

Outro fator que interferiu nos resultados das simulações estarem em condições de subestimação em relação aos dados medidos, tem haver com a variação de profundidade do na zona de aproximação da zona de praia, onde as estações de medições encontram-se. Por ser uma zona muito rasa, comprometendo em parte a batimetria, além, da influencia das correntes que ocorre nesta região e que não foi considerado nos cálculos da modelagem, sendo esta uma abordagem futura a ser considerada.

\subsection{Resultado das Análises Estatísticas dos dados Simu- lados e Dados Medidos}

Com relação às alturas significativas, os resultados para o erro quadrático médio apresentaram um comportamento similar ao erro, com os melhores resultados, e não tão bom para Tmed e DIR. O erro para HS foi sempre mais baixo que em relação os demais parâmetros da onda, o que era de se esperar uma vez que, as simulações de Tmed e DIR foram no geral subestimados em relação os dados medidos, principalmente nas características das simulações de Tmed de janeiro de 2011 e das direções de fevereiro de 2011 com as maiores disparidades apresentadas (Tabela 4). 
O coeficiente de correlação de Pearson calculado foi condizente nas alturas significativas nos conjunto de dados de janeiro e fevereiro de 2011, com tendência mais próxima de 1 , o que mostra uma correlação positiva para estes conjuntos de dados. Entretanto, para abril e agosto de 2012, o índice foi muito distante do esperado, sendo refletido nas simulações já apresentadas. No caso de dos dados de abril de 2012 (Tabela 9), foi muito baixo a correlação, visto que na própria condução da evolução da onda o comportamento da simulação foi distinto.

Nos casos de Tmed e DIR, os melhores resultados nos cálculos do coeficiente de correlação foram para os conjuntos de dados de janeiro e fevereiro de 2011 para Tmed (Tabelas 6 e 8), e, janeiro de 2011 e agosto de 2012 para DIR (Tabela 7 e 8). Em abril de 2012 (Tabela 9) foi o período dos menos aceitáveis estatisticamente e na própria simulação.

Em termos de HS uma forma de observar o comportamento do coeficiente de correlação é construindo o gráfico de dispersão (estes, acoplados às Tabelas com parâmetros estatísticos). Em cada gráfico de dispersão construído paras as alturas significativas nota-se que no geral os pontos distribuem se a partir da margem inferior esquerda para a margem superior direita, a exceção das alturas significativas de abril de 2012, mas nos casos de janeiro e fevereiro de 2011, a tendência foi semelhante.

Com base nos cálculos de $d$, índice de concordância entre os dados previstos e os medidos, confirma o que já foi apresentado nas análises estatísticas de RMSE e $R$, ou seja, as alturas significativas forma mais bem ajustadas para os casos de janeiro e fevereiro de $2011 \mathrm{e}$ agosto de 2012, com boa concordância entre os dados, $d=0.50,0.76$ e 0.50 . Sendo abril de 2012 o período com mais baixa concordância.

Nos casos de Tmed, os períodos de janeiro e fevereiro de 2011 e, apresentou boa concordância, $d$ $=0.61,0.51$, sendo os demais períodos muito abaixa da média de 0.50 . Para as direções, agosto de 2012 foi o que mostrou melhor concordância, com valor de $d$ mais aceitável, um pouco acima da média de 0.50 , e os demais, muito inferiores à média.

Após estas análises pode-se concluir que, com base nas simulações (Figuras 4 e 5) e nas análises dos parâmetros estatísticos (Tabelas 6 a 9) as alturas significativas apresentaram os melhores resultados. Os períodos médios foram mais condizentes no caso de fevereiro de 2011, com bom índice de concordância, $d=$ 0,61 e $R=0,53$. Entretanto, em termos de simulações os períodos médios mostraram-se sempre mais subestimados em relação aos medidos. Situação semelhante foi no caso das direções, com valores subestimados no geral.

As maiores disparidades observadas entre os valores pode estar relacionada com as diferenças entre os métodos dos cálculos que foi utilizado para cada conjunto de dado. Enquanto os dados in situ são calculados por meio de método direto, ou seja, é obtida a média

Tabela 6: Parâmetros estatísticos do conjunto de dados resultantes da modelagem e das medições do PT 1 para o período de 07 a 22 de fevereiro de 2011 e o gráfico de dispersão dos valores de HS.

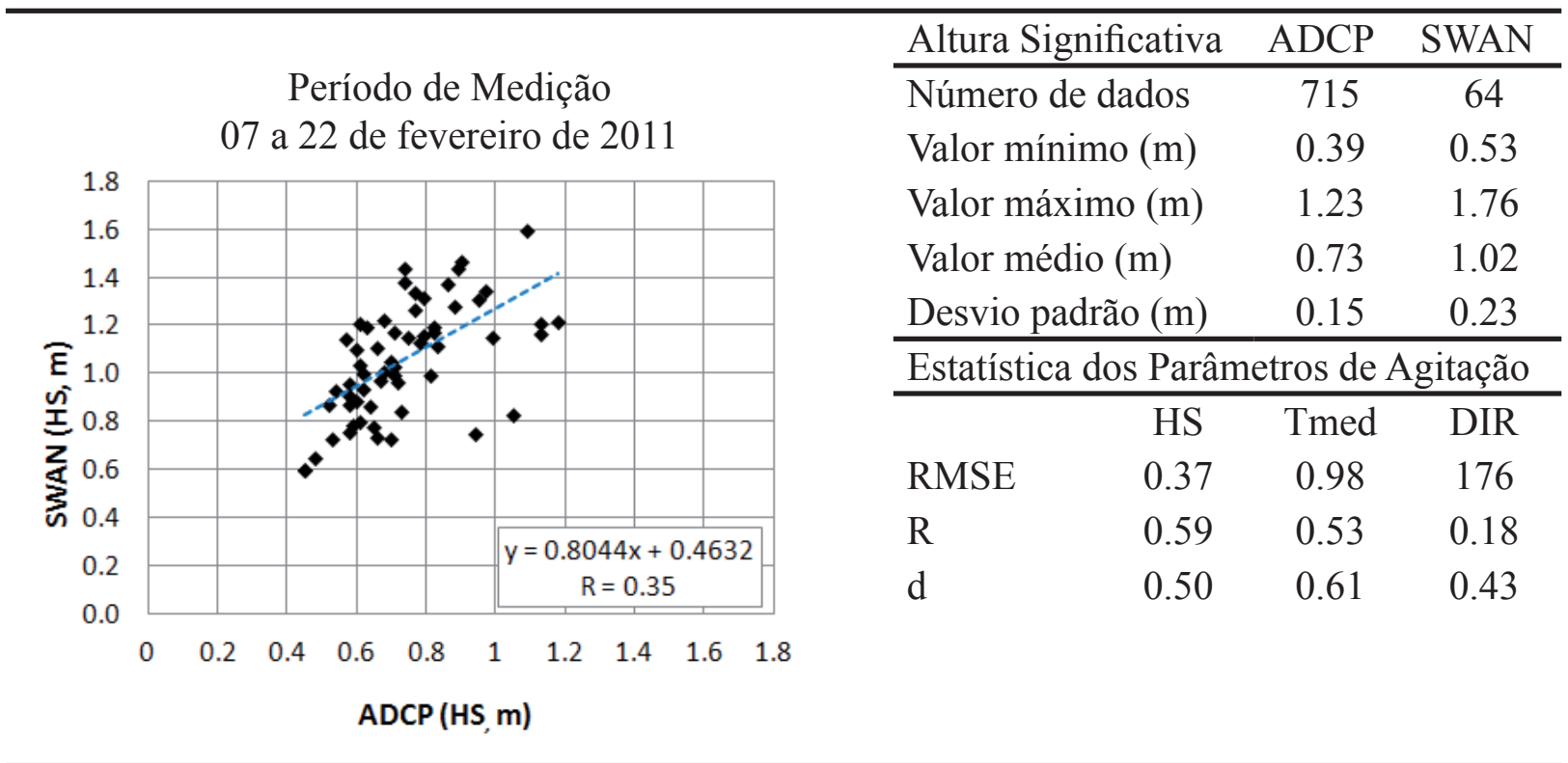


Tabela 7: Parâmetros estatísticos do conjunto de dados resultantes da modelagem e das medições do PT 1 para o período de 23 a 25 de agosto de 2012 e o gráfico de dispersão dos valores de HS.

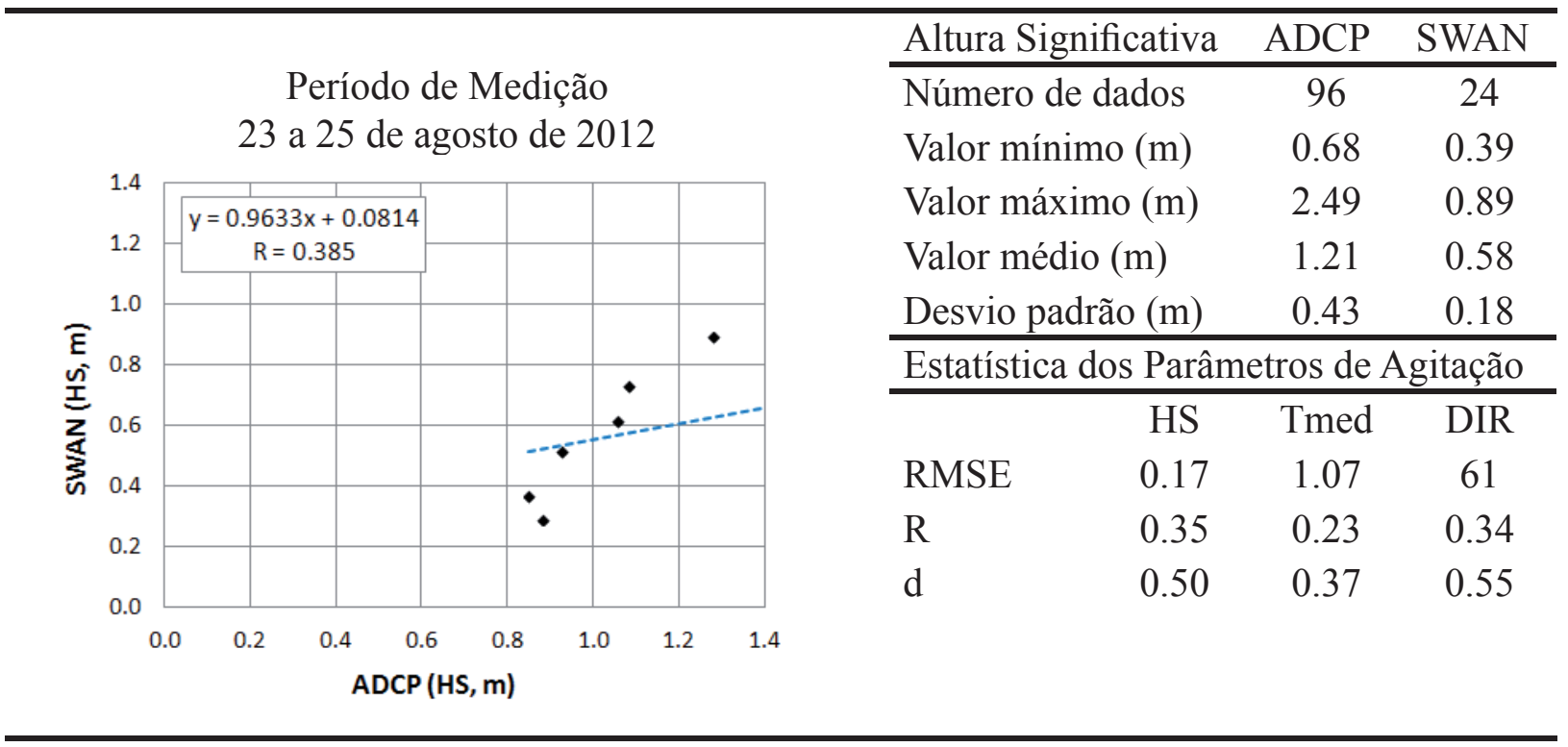

Tabela 8: Parâmetros estatísticos do conjunto de dados resultantes da modelagem e das medições do PT 2 para o período de 1 a 07 de janeiro de 2011 e o gráfico de dispersão dos valores de HS.

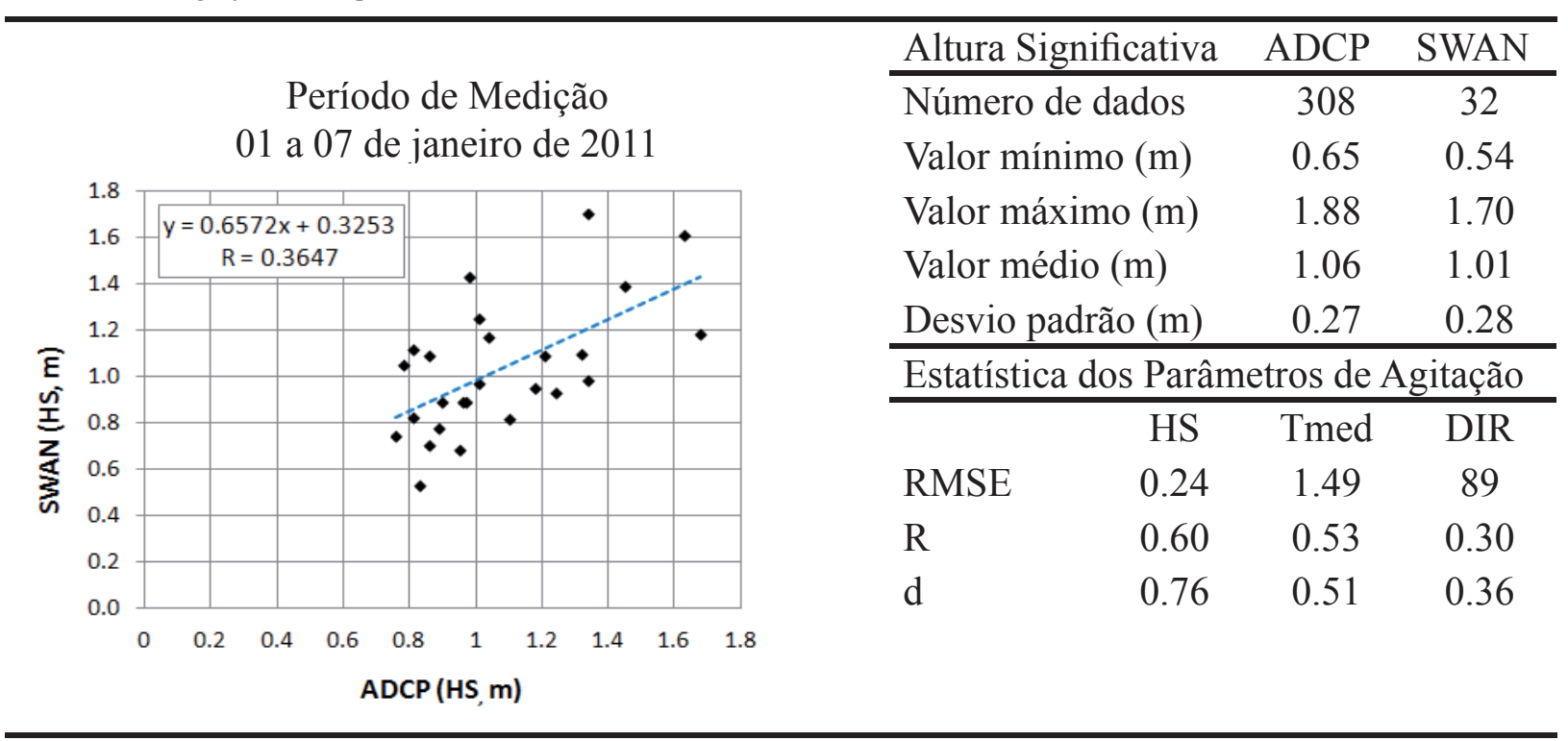

dos períodos entre os zeros ascendentes a partir de um determinado registro, no caso dos dados simulados, os parâmetros são calculados por meio do método espectral. Se o registro da estação de medição ou da boia oceânica, tiver amostragem muito diferente em termos de aquisição, os dados podem não representar o parâmetro na realidade e causar disparidades entre os valores.

Tanto Tmed quanto DIR foram confirmados nas estatísticas com erros muito altos, correlação muito baixa e índice de concordância mais ajustável em alguns casos, como o ocorrido para o conjunto de dados de agosto de 2012, tendência esta esperada, uma vez que as direções é um parâmetro mais complexo de se obter bons resultados, devido os fenômenos físicos envolvidos, como por exemplo, os efeitos da refração e difração da onda, a medida que esta se propaga em direção a praia. Devido sua difícil representatividade, nem sempre é um parâmetro usado para as comparações entre os previstos e os simulados. 
Tabela 9: Parâmetros estatísticos do conjunto de dados resultantes da modelagem e das medições do PT 2 para o período de 17 a 24 de abril de 2012 e o gráfico de dispersão dos valores de HS.

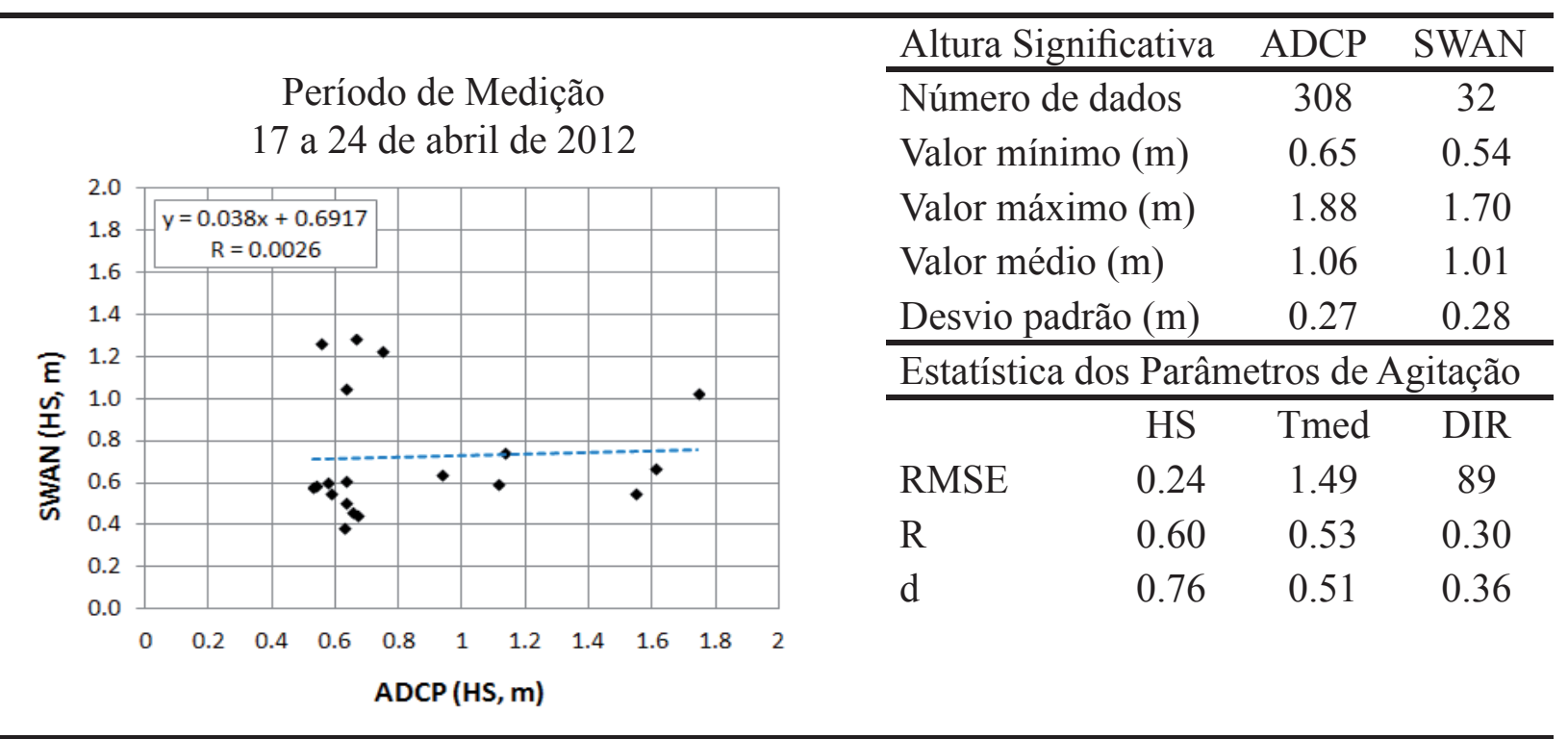

Diante desta análise, buscou-se obter algumas comparações de outros autores de outros lugares do mundo com semelhantes valores estatísticos ao comparar os resultados obtidos pelo modelo SWAN com os obtidos das estações de medições, tais como os resultados obtidos por LIN et al. (2002) $(R=0,51$ para HS e $R=0,12$ para Tp) e MOEINI e ETEMAD-SHAHIDI (2009) $(R=0,83$ para HS e $R=0,48$ para Tp). Ambos utilizaram o modelo SWAN para simulação de ondas na Baía de Chesapeake e do Lago Erie, respectivamente, e nos dois casos as alturas significativas foram sempre mais ajustadas, período médio com indicadores estatísticos mais inferiores. Também analisando os resultados obtidos por AKPINAR et al. (2012) $(R=0.67$ para HS e $R=0.42$ Tmed), que aplicou o SWAN para simular as ondas do Mar Negro, novamente percebeu-se que as alturas significativas obtiveram melhores resultados e, em todos os casos, obtiveram uma ligeira subestimação na previsão dos parâmetros de ondas para os períodos simulados. Nota-se então, que em nenhum dos casos foi feito referencia as direções.

\subsection{Resultado da Distribuição Espacial da Onda na Plataforma Continental do RN}

Com base na validação dos dados da simulação do SWAN, em reproduzir o clima de ondas para a região do litoral do Rio Grande do Norte, este item apresenta a caracterização do clima de agitação marítima para este litoral.

O Rio Grande do Norte possui uma costa aberta, para norte e a leste, exposta às condições marítimas do Oceano Atlântico. Devido sua localização, na região equatorial de máxima temperatura superficial do mar e onde corre a convergência dos ventos alísios, caracteriza-se a Zona de Convergência Intertropical - ZCIT, responsável principalmente pelo regime de ventos neste litoral e geração de uma ondulação predominante de nordeste, caracterizando assim, uma agitação marítima com certa constância ao longo do ano devido à variabilidade sazonal.

As análises da distribuição espacial da altura significativa e das direções da onda (Figuras 6 e 7) permitem observar o efeito da evolução em toda a zona da plataforma continental do $\mathrm{RN}$ em dois momentos distintos: um estado de mar típico de um dia de verão, que compreende um dia do mês de janeiro, (Figura 6); e outro momento de agitação marítima de um dia típico de inverno, compreendo o mês de agosto (Figura 7).

É possível verificar alteração de valores e estados de mar bastante significativos nos dois momentos. A direção média tende a aproximar-se mais do Norte para o mês de janeiro, caracterizado por ondas predominantemente de nordeste, considerado este como o período de verão, observa-se maiores alturas de ondas se aproximando da costa neste período. 


\section{Interação entre Ondas Oceânicas e Fundo Marinho: Resultados na Plataforma Continental Setentrional}

No segundo momento, no período de inverno, verifica-se um estado de mar mais agitado, típico de uma agitação de incidência de ventos locais, com direções médias se aproximando da costa em ângulo mais refratado (do componente leste para nordeste), coincidindo com o período de alterações dos ventos que neste período recebem maior domínio dos ventos alísios de sudeste, ou impulsionado pela corrente de deriva litorânea nesta zona próxima à costa, ou ainda pode estar associada a componente de maré vazante. Nota-se que as alturas da onda são muito baixas ao aproximarem-se de costa.
Não foram registradas alterações acentuadas nos valores de HS entre um período e outro, o que caracterizaria estado de agitação marítima mais severa. Nota-se que a escala de valores máximos foi de $2.5 \mathrm{~m}$ para ambos os casos, entretanto, o que se observou foi às alterações de HS em termos de distribuição espacial ao aproximar-se da costa.

Então, a ondulação nordeste é mais intensa na região durante o mês de verão, e de inverno recebe maior influencia de leste e sudeste.

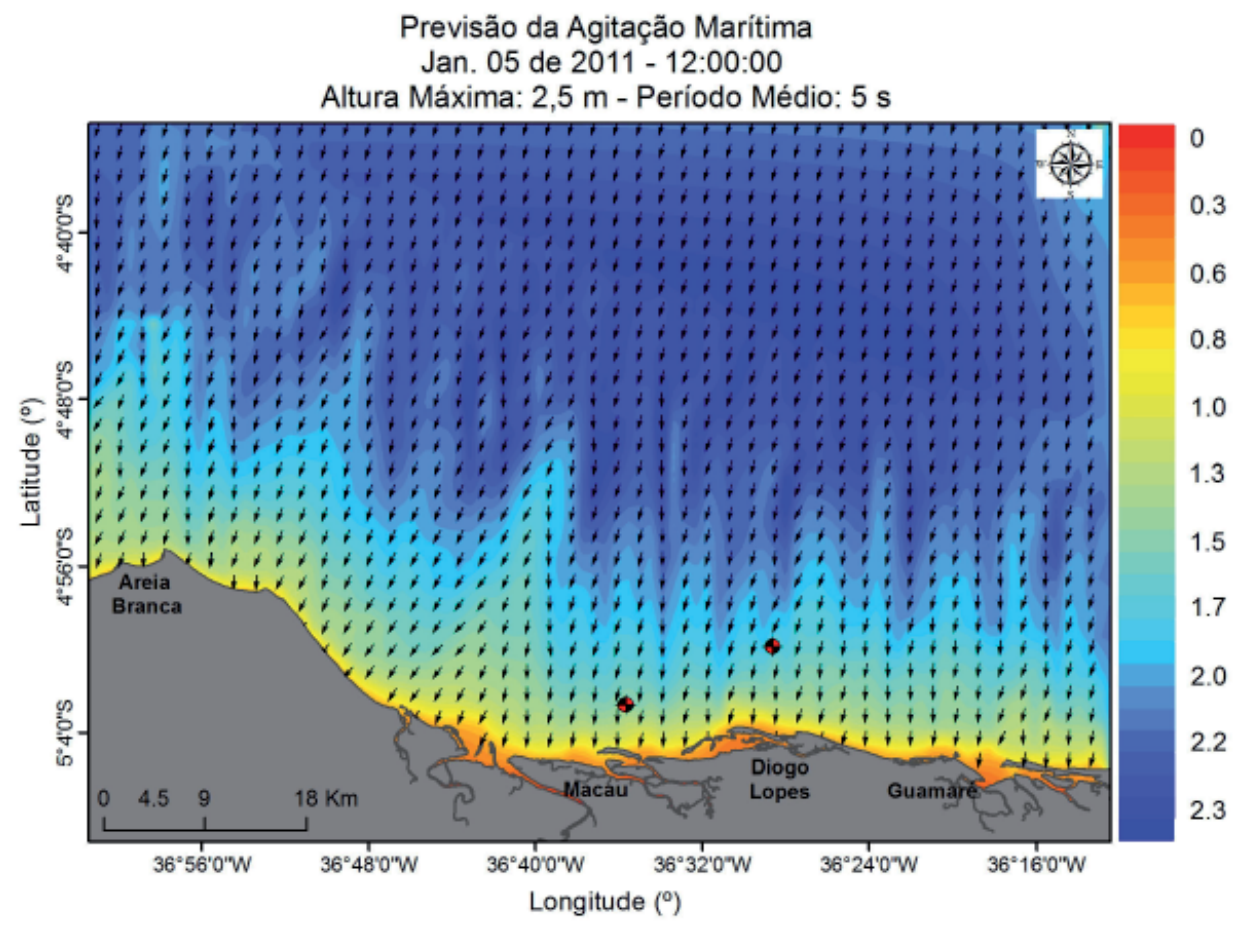

Figura 6 - Resultados das simulações do SWAN no domínio computacional para o dia 05 de janeiro de 2011, às 12:00h, para HS e com os vetores da direções médias.

\subsection{Análise da Evolução Espacial do Clima de Ondas e sua Interação com a Compartimentação Submarina da Plataforma Continental}

As zonas costeiras são caracterizadas principalmente pela complexidade hidrodinâmica, resultante da interação de ondas, correntes e ventos com os fundos marinhos.

A plataforma continental do litoral setentrional do Rio Grande do Norte é de profundidade rasa, onde os efeitos de águas rasas podem desempenhar um importante papel na configuração do relevo submerso. Devi- do sua abertura ser voltada para norte $(\mathrm{N})$, e levando em conta seu posicionamento geográfico, fortemente afetado pela zona de confluência dos alísios (ZCA), este setor recebe ondas principalmente dos quadrantes: norte $(\mathrm{N})$, nordeste (NE) e leste-sudeste (E-SE), como já foram observados.

Para analisar a evolução da onda e sua interação com a compartimentação do fundo marinho, observou-se a evolução da onda a partir de um perfil espacial transversalmente a costa (Figura 8), onde se buscou correlacionar a evolução da onda com as formas de fundo presente e identificadas por GOMES e VITAL (2010) 


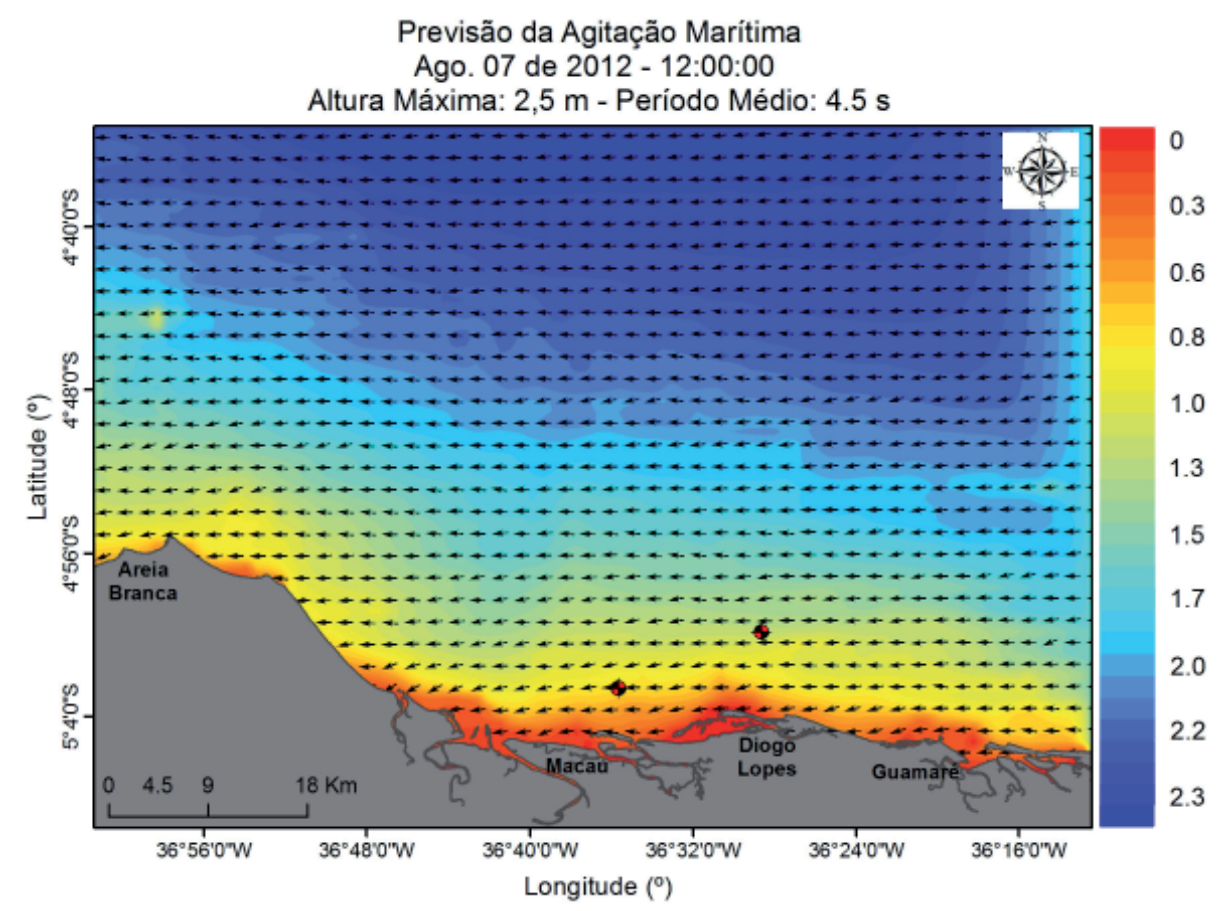

Figura 7 - Resultados das simulações do SWAN no domínio computacional para o dia 07 de agosto de 2012, às 12:00h, para HS com os vetores da direções médias.

e CABRAL NETO (2011) da plataforma continental.

A interação das ondas com os fundos marinhos de plataformas rasas, 0 - $30 \mathrm{~m}$ podem ser caracterizadas em três etapas: a) o empolamento, que consiste na diminuição do comprimento de onda e do aumento da amplitude e da assimetria da onda; b) a rebentação onde ocorrem os processos de dissipação e de transferência de energia da onda, responsáveis pela geração de correntes litorais que são os escoamentos mais importantes, em termos de velocidade e de capacidade de transporte sedimentar; $\mathbf{c})$ e, o espraiamento da onda na face da praia. Fenômenos estes considerados nos cálculos do SWAN, versão 40.72 AB. Fora da zona de arrebentação, o atrito de fundo é geralmente o mais relevante.

A percepção de tais processos envolvidos na propagação da onda desde ao largo até seu espraiamento foi baseada na adaptação da determinação da distribuição espacial do parâmetro adimensional HS/d (AKKPINAR et al., 2012), que mostra a variação da altura significativa da onda $(\mathrm{HS},(\mathrm{m}))$ em relação à profundidade $(\mathrm{d},(\mathrm{m}))$ em uma secção de um perfil transversal sentido norte (N) para sul (S), variante nas profundidades iniciais das isóbatas acima de $40 \mathrm{~m}$ até às profundidades próximas à linha de praia, de $0.5 \mathrm{~m}$. O parâmetro direcional das ondas (), fora incluído para analisar o efeito da refração da onda.

No perfil analisado (Figura 9), os momentos de agitação escolhidos foram os dias: 05 de janeiro às 12:00 horas, e 18 de fevereiro às 18: 00 horas, em 2011, sob condições de ventos de $9,6 \mathrm{~m} / \mathrm{s}$ e com direções médias de $70^{\circ}$, e $9,8 \mathrm{~m} / \mathrm{s}$ e direções médias $16^{\circ}$, respectivamente. A seção transversal do perfil é de $35 \mathrm{~km}$ de distância, onde a latitude inicial é YI = 9473842-S, na profundidade de $57 \mathrm{~m}$ e, latitude final, seguindo o sentido para a costa de $\mathrm{YF}=9439842-\mathrm{S}$, na profundidade de $1 \mathrm{~m}$, seção esta ao longo da longitude $\mathrm{X}=783000-\mathrm{W}$.

Nas condições do perfil, tanto as condições em (A) quanto em (B), os efeitos do fundo foram mais evidentes no P1 durante a passagem da onda pela sequência dos campos de dunas longitudinais simétricos e assimétricos, próximo a $4 \mathrm{~m}$ de profundidade e distância de $10 \mathrm{~km}$ da costa, apesar de haver um leve crescimento em relação a passagem pelo $\mathrm{P} 3$, caracterizado por algumas estruturas de dunas transversais. As mudanças das direções foram mais bruscas sempre nas passagens das feições geomorfológicas, refratando da direção máxima de $40^{\circ}$ (águas mais profundas) para cerca de $16^{\circ}$ próximo da costa. 


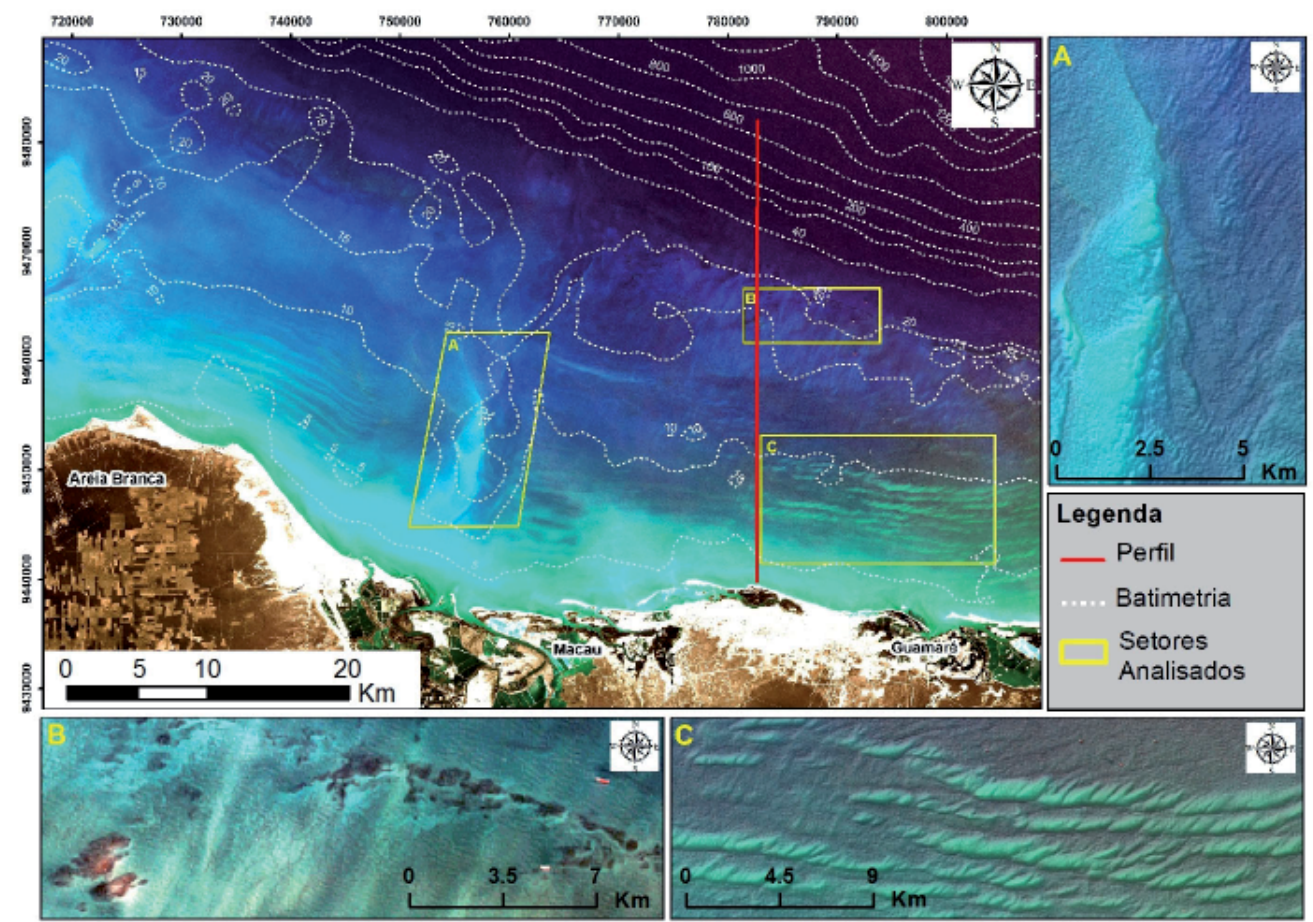

Figura 8 - Mapa exemplificando setores do relevo submerso. Em destaque o perfil transversal, a batimetria e: a) paleocanal do rio Açú; b) linhas de rochas praiais (beachrocks); e, c) campos de dunas longitudinais simétricas e assimétricas (GOMES et al., 2010).

Estas análises mostram a importância do papel do atrito de fundo quando as ondas entram em águas mais rasas, principalmente, na borda da zona costeira e nos setores proeminentes do relevo submarino. Nestas condições, à medida que as ondas se propagam em direção à costa, há alterações da altura significativa da onda e das direções. Ela tende a alterar inicialmente ao entrar na zona da plataforma externa (profundidades acima de $40 \mathrm{~m}$ ), a partir da qual estão presentes linhas de rochas praiais (beachrocks) que se dispõe em extensa linha de leste a oeste, a partir da zona de rochas praiais, as ondas tendem a variar nas alturas até a zona de dissipação e espraiamento da onda na zona de rebentação da praia, como pode ser observado na Figura 9.

\section{Conclusões}

Este artigo apresenta uma visão detalhada da modelagem numérica por meio do modelo de ondas SWAN, para várias condições de agitação incidentes, com vista a caracterizar o clima de ondas e investigar sua interação com o fundo marinho raso da plataforma continental setentrional do Rio Grande do Norte.
Na primeira fase do trabalho, o modelo SWAN foi aplicado na propagação de várias condições de agitação incidente até junto à costa, com uso das formulações padrões do modelo, em condição de regime estacionário, sendo o resultado da modelagem comparado aos medidos.

No detalhamento das análises, os resultados revelaram que o SWAN conseguiu reproduzir as condições de agitação e de modo geral, o modelo reproduziu as tendências de crescimento e decaimento das alturas significativas da onda, incluindo os momentos de sobreposição dos episódios de ondulações mais expressivas. As alturas significativas alcançaram resultados mais aceitáveis, ou maior ajustamento dos dados, com melhores resultados simulados e estatísticos.

Em termos de períodos médios, notadamente as análises foram menos precisas, e no geral, Tmed, esteve quase sempre condicionado uma subestimação do modelo, fato este, explicado pelos atributos de fronteira, componentes de ventos e marés onshore, e do valor atribuído à condição padrão do modelo SWAN, com coeficiente de atrito de fundo $c=0.015 \mathrm{~m}^{2} \mathrm{~s}^{-3}$, ora superestima as alturas significativas ou ora subestima os 
(A)

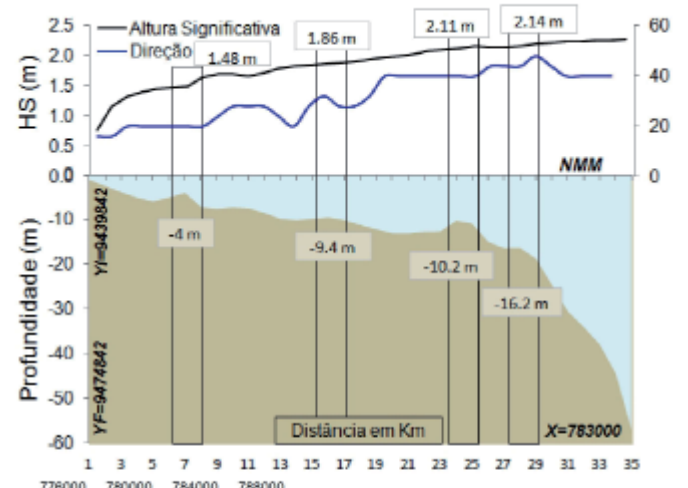

(B)
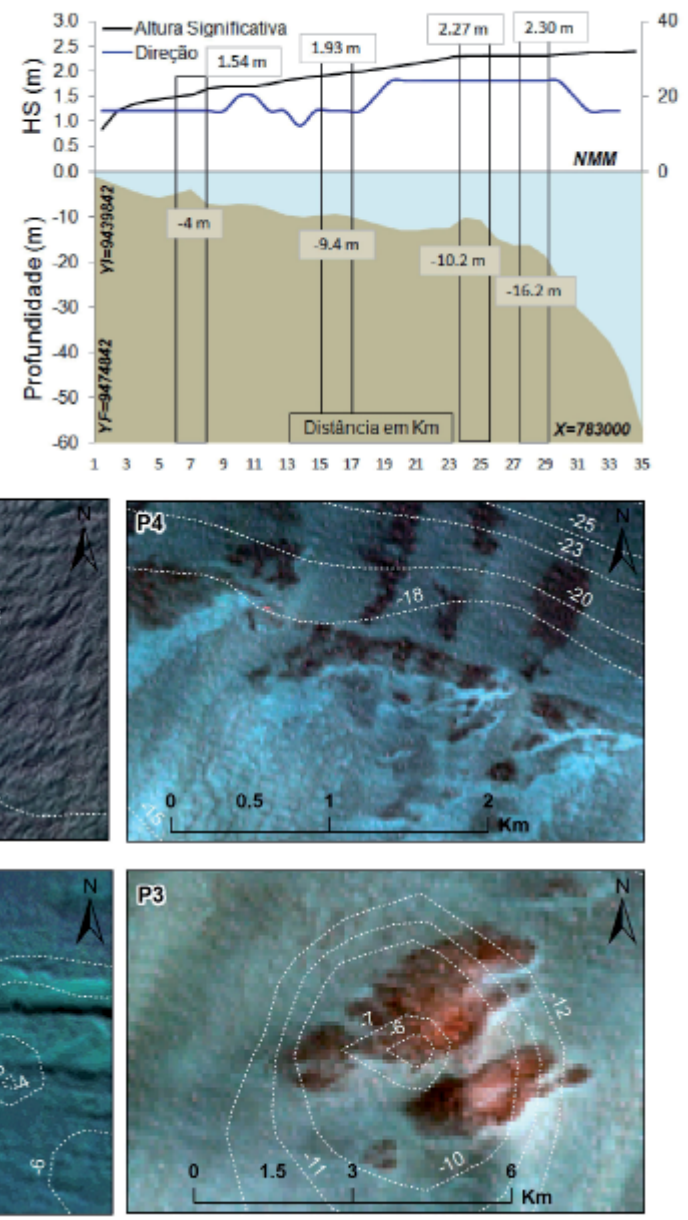

Figura 9: Perfil transversal à costa, indicando a evolução da onda: A) condição de agitação de 05/01/2011, às 12:00h; B) 18/02/2011, às 18:00h. Com as associações das formas de fundo: P1, campos de dunas longitudinais simétricas e assimétricas; P2, dunas subaquáticas; P3 e P4, beachrocks.

períodos médios. Além do uso da formulação KOMEN para todo o conjunto da modelagem pode ter influenciado nos dados simulados, resultando em maiores disparidades. $\mathrm{O}$ uso de uma mesma formulação para todo o conjunto de dados nem sempre reproduz os melhores resultados para todos os parâmetros. Sugerindo que o valor do atrito de fundo é importante se considerado, e a forma mais adequada é o uso do melhor valor que ajuste e modele melhor cada parâmetro estudado.

Outro fator que explica as maiores disparidades observadas entre os valores pode estar relacionada com as diferenças entre os métodos dos cálculos que foi utilizado para cada conjunto de dado. Os dados in situ são calculados por meio de método direto, ou seja, é obtida a média dos períodos entre os zeros ascendentes a partir de um determinado registro, no caso dos dados simulados, os parâmetros são calculados por meio do método espectral. Se o registro da estação de medição ou da boia oceânica tiver amostragem muito diferente em termos de aquisição, os dados podem não representar o parâmetro na realidade e causar disparidades entre os valores.

Outros fatores que influenciaram nas comparações das previsões e medições, estão relacionados às baixas profundidades dos pontos de medições muito próximos da costa, onde as correntes ocorrem com maior intensidade nesta região e que não foram consideradas nos cálculos da modelagem, sendo esta uma abordagem futura a ser considerada nos próximos trabalhos. 
Em termos de padrões de agitação marítima, a ondulação nordeste é mais intensa na região durante o mês de verão, representado pelo mês de janeiro, e de inverno, mês de agosto, recebe maior influencia de onda de leste e do componente sudeste.

E por fim, na análise da evolução da onda em águas rasas por meio do perfil transversal, observou-se que no perfil analisado para todas as condições de agitação, tanto a amplitude da onda quanto as direções estão sujeitas as alterações (empolamento, rebentação e dissipação) ao interagir com as formas de fundo (beachrocks, dunas longitudinais simétricas e assimétricas, dunas transversais, dunas subaquáticas paralelas à costa), presente ao longo das plataformas externas, média e interna, caracterizando para esta plataforma continental que o mecanismo de dissipação dominante à propagação das ondas nestas águas rasas é o atrito de fundo.

\section{Agradecimentos}

Os autores agradecem a CAPES, pela concessão da bolsa durante o doutorado; à Rede Amigos Boussinesq e CAPES/FCT (Fundação para Ciência e Tecnologia), pelo financiamento concedido durante o doutorado-sanduíche no Laboratório Nacional de Engenharia Civil de Portugal, através dos Projetos PTD/ECM/73145, PTD/AMB/67450/2006 e PTDC/ECM/67411/2006 e os projetos cooperativos HIDROSEMA e MOLECO, da Rede de Monitoramento: REDE5-PETROMAR/ CTPETRO-FINEP/PETROBRAS/CNPq, que financiaram esta pesquisa.

\section{Referências Bibliográficas}

AKPINAR, A.; VAN VLEDDER, G. P.; KÖMÜRCÜ, M. I.; ÖZGER, M. Evaluation of the numerical wave model (SWAN) for wave simulation in the Black Sea. Continental Shelf Research, v. 50, n. 19, p. 80-99, 2012.

ÂNGElo, J. S. F. C. Aplicação do modelo SWAN na caracterização da agitação marítima na zona adjacente ao estuário de Diogo Lopes, Brasil. 2012. 79f. Dissertação (Mestrado em Engenharia Civil) - Instituto Superior Técnico de Lisboa, Portugal. 2012.

ARAÚJO, M. C.; JORGENSEN, S. E. Modelagem ecológica de reservatórios. In: TUNDISI, J. G. (ed.), Limnologia e Manejo de Represas. Academia de Ciências do Estado de São Paulo, v. 1, p. $395-402,1988$.
ARORA, C.; BHASKARAN, K. P. Numerical modeling of suspended sediment concentration and its validation for the Hooghly Estuary, India. Coastal Engineering Journal, v. 55, n. 2, p. 1-23, 2012.

BATTJES, J. A.; JANSSEN, J. P. F. M. Energy loss and setup due to breaking of random waves. In: PROCEEDINGS OF INTERNATIONAL CONFERENCE ON COASTAL ENGINEERING, 16, 1978, Hamburg. Abstract... Hamburg: ASCE, 1978. p. 569-587.

BOOIJ, N.; RIS, R. C. HOLTHUIJSEN, L. H. A third-generation wave model for coastal regions, part I, model description and validation. Journal Geophysical Research, v. 104, n. 4, p. 7649-7666, 1999.

CABRAL NETO, I. Beachrocks do rio grande do norte: correlação entre os depósitos costeiros e os de zona costaafora com base na faciologia, petrografia e diagênese. 2011. 148f. Dissertação (Mestrado em Geodinâmica) - Universidade Federal do Rio Grande do Norte, Natal, 2011.

CAPITÃO, R.; FORTES, C. J. E. M. Análise comparativa entre estimativas do modelo SWAN e medições de agitação marítima efetuadas na Praia de Amoreira, Portugal. Revista da Gestão Costeira Integrada, v. 11, n. 3, p. 283-296, 2011.

CUCHIARA, D.; FERNANDES, E. H.; STRAUCH, J. C.; CALLIARI, L. J. Modelagem numérica do comportamento de ondas na costa do Rio Grande do Sul. In: SEMINÁRIO E WORKSHOP EM ENGENHARIA OCEANICA, 2, 2006, Rio Grande. Anais... Rio Grande: UFRG, 2006, p.15.

DHN. DIRETORIA DE HIDROGRAFIA E NAVEGAÇÃO (Brasil). Tábuas de marés. Disponível em: $<$ http://www.dhn. mar.mil.br/ >. Acesso em Out 2009.

DHN. DIRETORIA DE HIDROGRAFIA E NAVEGAÇÃO (Brasil). Cartas náuticas. Disponível em: $<$ http://www.dhn. mar.mil.br/ >. Acesso em Jan 2012.

ELDEBERKY, Y. Nonlinear transformation of wave spectra in the neashore zone. 1996. Thesis - The Delft University of Technology, Department of Civil Engineering, Netherlands. 1996.

FORTES, C. J. E. M.; NEVES, M. G.; ZÓZIMO, A. C.; COLI, A. B.; COVAS, J. Aplicação de modelos numéricos de estudo de propagação de ondas marítimas em zonas costeiras. In: CONGRESSO DA ÁGUA, 7, 2004, Lisboa. Actas ... Lisboa: APRH (versão eletrônica), 2004.

FORTES, C. J. E. M.; PINHEIRO, L.; PALHA, A. O pacote de dados SOPRO: evoluções recentes. In: JORNADAS 
PORTUGUESAS DE ENGENHARIA COSTEIRA E PORTUÁRIA, 5, 2007, Lisboa. Anais... Lisboa: APRH/PIANC (versão eletrônica), 2007.

GOMES, M. P.; VITAL, H. Revisão da compartimentação da plataforma continental Norte do Rio Grande do Norte, Brasil. Revista Brasileira de Geociências, v. 40, n. 3, p. 321-329, 2010. HASSELMANN, K.; BARNETT, T. P.; BOUWS, E.; CARLSON, H.; CARTWRIGHT, D. E.; ENKE, K.; EWING, J. A.; GIENAPP, H.; HASSELMANN, D. E.; KRUSEMAN, P.; MEERBURG, A.; MLLER, P.; OLBERS, D. J.; RICHTER, K.; SELL, W.; WALDEN, H. Measurements of wind wave-growth and swell decay during the Joint_North Sea Wave Project (JONSWAP), Deutches Hydrographisches Institut. v. 12, n. 8, p. 1-95, 1973.

HASSELMANN, K. On the spectral dissipation of ocean waves due to whitecapping. Boundary-Layer Meteorology, v. 6, n. 2, p. 107-127, 1974.

HASSELMANN, S.; HASSELMANN, K.; ALLENDER, J. H.; BARNETT, T. P. Computations and parameterizations of the linear energy transfer in a gravity wave spectrum, Part II: parameterizations of nonlinear transfer for application in wave models. Journal of Physical Oceanography, v. 15, n.11, p. 1378-1391, 1985.

HOLTHUIJSEN, L. H.; BOOIJ, N.; RIS, R. C.; HAAGSMA, I. J. G.; KIEFTENBURG, A. T. M. M.; PADILLA-HERNANDEZ, R. SWAN Cycle 2 version 40.01. User Manual. Delft University of Technology, The Netherlands, 1999.

HOUTHUIJSEN, L. H.; HERMAN, A.; BOOIJ, N. Phasedecoupled refraction-diffraction for spectral wave models. Coastal Engineering, v. 49, 291-305, 2003.

INMET. INSTITUTO NACIONAL DE METEOROLOGIA (Brasil). Dados das séries temporais climáticas da Rede do INMET. Disponível em: < http://www.inmet.gov.br/> Acesso em: Jan 2012.

KOMEN, G. J.; HASSELMANN, S.; HASSELMANN, K. On the existence of a fully developed windsea spectrum. Journal of Physical Oceanography, v. 14, p.1271-1285, 1984.

LIMA, Z. M. C.; VITAL, H.; TABOSA, W. F. Morphodynamic variability of the Galinhos Spit, NE Brazil. Journal of Coastal Research, v. 39, p. 598-601, 2006.

LIN, W.; SANFORD, L. P.; SUTTLES, S. E. Wave measurement and modeling in Cheasepeake Bay. Continental Shelf Research, v.22, p. 2673-2686, 2002.

MATOS, M. F. A.; FORTES, C. J. E. M.; AMARO, V. E.;
SCUDELARI, A. C. Análise comparativa da agitação obtida com o modelo numérico (SWAN) na modelagem de ondas do Litoral Setentrional do Rio Grande do Norte, Brasil e dados de campo. Revista de Gestão Costeira Integrada, v. 13, n. 3, p. 283-299, 2013.

MATOS, M. F. A. Modelagem do clima de ondas e seus efeitos sobre as feições morfológicas costeiras no Litoral Setentrional do Rio Grande do Norte. 2013. 225f. Tese (Doutorado em Geodinâmica) - Universidade Federal do Rio Grande do Norte, Natal, 2013.

MOEINI, M. H.; ETEMAD-SHAHIDI, A. Wave parameter hindcasting in a lake using the SWAN model. Transaction A: Civil Engineering, v.16, n.2, p. 156-164, 2009.

PADILLA-HERNÁNDEZ, R.; MONBALIU, J. Energy balance of wind waves as a function of the bottom friction formulation. Coastal Engineering, v. 43, p. 131-148, 2001.

PIRES SILVA, A. A.; MAKARYNSKYY, O.; MONBALIU, J.; VENTURA SOARES, C.; COELHO, E. Modelling wave transformation in an open beach on the west coast of Portugal. In: PROCEEDING COASTAL WAVE MEETING, A. SANCHEZ-ARCILLA, S. PONCE DE LEON (Eds.), Technical University of Catalonia, Barcelona, Chapt. 4.3, 2000.

RIS, R. C. Spectral modelling of wind waves in coastal areas.1997. PhD Thesis. Delft University of Technology, The Netherlands, 1997.

RIS, R. C.; HOLTHUIJSEN, L. H.; BOOIJ, N. A third-generation wave model for coastal region: 2. Verification. Journal of Geophysical Research, v. 104, n.4, p. 7667-7681, 1999.

ROSMAN, P. C. C.; NEVES, C. F.; MUEHE, D.; VALENTINI, E. M. S. Estudos de vulnerabilidades no Litoral do Estado do Rio de Janeiro devido às mudanças climáticas. Fundação Coppetec PENO-9501, Relatório Final, 98p, 2007.

SAMPAIO, M. J. R. T. Aplicação do modelo SWAN na caracterização da agitação marítima na zona adjacente a Pinheiro da Cruz. 2008. 66f. Dissertação (Mestrado em Engenharia Civil) - Instituto Superior Técnico de Lisboa, Portugal, 2008.

TABOSA, W. F.; VITAL, H. Hydrodynamic forcing and environmental impacts on the coasts and shelf adjacent to São Bento do Norte, NE Brazil. In: Brebbia C.A. (eds.) Environmental Problems in Coastal Regions VI: Including Oil Spill Studies. Wessex Institut of Tecnology, Cambridge Printing, p.165-174, 2006.

TABOSA, W. F.; AMARO, V. E.; VITAL, H. Caracterização do 
ambiente costeiro, integrado a produtos de sensoriamento remote na região de São Bento do Norte/Caiçara do Norte-NE Brasil. Revista Brasileira de Geofísica, v. 25, n. 1, p. 37-48, 2007.

TELES, M. J.; PIRES SILVA, A. A.; BELO-PEREIRA, M. Simulations of wave conditions on open beach configuration: Wind resolution, seaward forcing and whitecapping effects. European Journal of Environmental and Civil Engineering, v. 16, n. 8, p. 927-942, 2012.

TOLMAN, H. L. User manual and system documentation of WAVEWATCH - III Version 2.22. N.O.A.A. National Centers for Environmental Prediction. OMB Technical Note 222. Camp. Springer, EUA, 133p, 2002.

VITAL, H.; SILVEIRA, I. M.; AMARO, V. E. Carta Sedimentológica da Plataforma Continental Brasileira - Área Guamaré a Macau (NE BRASIL),Utilizando Integração de dados Geológicos e Sensoriamento Remoto. Revista Brasileira de Geofísica, Rio de Janeiro, v. 23, n.3, p. 233-241, 2005.
VITAL, H.; STATTEGGER, K.; AMARO, V. E.; SCHWARZER, K.; FRAZÃO, E. P.; TABOSA, W. F. Mopdern high-energy siliciclastic-carbonate plataform: Brazilian Continental Shelf Adjacent to Northern Rio Grande do Norte State, NE Brazil. SEPM Special Publication on Advances in Shallow-marine sedimentology. Journal of Sedimentary Research, v. 90, p. $100,2008$.

WAMDI GROUP. The WAM model - a third generation ocean wave prediction model. Journal of Physical Oceanography, v. 18 , p. 1775-1810, 1988.

WILMOTT, C. J. On the validation of models. Physical Geography, v. 2, p. 1984 - 1994, 1981.

ZIJLEMA, M.; VAN DER WESTHUYSEN, A. J. On convergence behaviour and numerical accuracy in stationary SWAN simulations of nearshore wind wave spectral, Coastal Engineering, v. 52, 237-256, 2005. 